Revista lus et Praxis, Año 25, No 1, 2019, pp. 89 - 130

ISSN 0717 - 2877

Universidad de Talca - Facultad de Ciencias Jurídicas y Sociales

La tutela meramente declarativa o de mera certeza y su reconocimiento

en el sistema procesal civil chileno

Renée Marlene Rivero Hurtado

Trabajo recibido el 16 de abril y aprobado el 12 de septiembre de 2018

\title{
La tutela meramente declarativa o de mera certeza y su reconocimiento en el sistema procesal civil chileno*
}

\author{
THE ACTION FOR DECLARATORY JUDGMENT AND ITS RECOGNITION UNDER \\ THE CHILEAN CIVIL PROCEDURE SYSTEM
}

Renée Marlene Rivero Hurtado**

\begin{abstract}
RESUMEN
El presente trabajo tiene por objeto examinar el origen y perfiles esenciales de la denominada acción meramente declarativa o declarativa de mera certeza como una función propia y clave de la potestad jurisdiccional que detentan los órganos jurisdiccionales para la tutela preventiva y la certeza prejudicial de los derechos e intereses legítimos de los justiciables y su reconocimiento y aplicación en el sistema procesal civil chileno.
\end{abstract}

\section{ABSTRACT}

This article delves into the origin and essentials features of what has been denominated declaratory judgement or action for declaratory judgment as a critical function of the judicial authority held by the court in order to provide preventive protection of rights and legitimate interests of the parties and its recognition and application under the Chilean civil procedure system.

\section{PALABRAS CLAVE}

Acción meramente declarativa, acción declarativa de mera certeza, mera certeza

KEY WORDS

Declaratory judgments, preventive protection of rights, declaration of rights by court

\section{Introducción}

Los últimos pronunciamientos del Tribunal Constitucional y del Senado en las contiendas de competencia suscitadas por la Contraloría General de la República, a propósito del estatuto jurídico previsional aplicable a los

\footnotetext{
* Nuestro especial agradecimiento al Prof. Cristián Maturana Miquel, Profesor Titular del Departamento de Derecho Procesal, Facultad de Derecho, Universidad de Chile y al prof. Jesús Ezurmendia Álvarez, Profesor Asistente del Departamento de Derecho Procesal, Facultad de Derecho, Universidad de Chile, por los valiosos comentarios y sugerencias a este trabajo.

** Abogada, Licenciada en Ciencias Jurídicas y Sociales, Universidad de Chile; Doctora en Derecho Universitat de Valéncia, España; Profesora de Derecho Procesal, Facultad de Derecho, Universidad de Chile, rrivero@derecho.uchile.cl. Dirección: Av. Santa María № 076, oficina 502, Providencia, Santiago de Chile.
} 
funcionarios de la Dirección General de Aeronáutica Civil, ha hecho resurgir un tema olvidado y escasamente tratado por la dogmática procesal chilena pero, al mismo tiempo, de gran utilidad y aplicación práctica, como es la denominada acción meramente declarativa o declarativa de mera certeza, la que ha llegado a ser calificada por parte de la doctrina más autorizada como "la función más delicada, más elevada, más autónoma del proceso" ${ }^{1}$ destinada a dar certeza y seguridad jurídica a los derechos e intereses legítimos de las partes, previniendo o despejando toda situación de incertidumbre o desconocimiento de los mismos.

El presente trabajo tiene por objeto examinar el origen y perfiles esenciales de este tipo de tutela y su reconocimiento y relevancia en el sistema procesal civil chileno como una función propia y clave de la potestad jurisdiccional que detentan los órganos jurisdiccionales tanto para la tutela preventiva como para la certeza prejudicial de los derechos e intereses legítimos de los justiciables, potestad que se aparta de la tradicional concepción esencialmente represiva que siempre se ha sostenido respecto de la función jurisdiccional.

En esta línea, se revisará, brevemente, el origen y evolución de esta institución y su relevancia, reconocimiento y aplicación en los sistemas anglosajón y europeo continental así como en el propio ordenamiento chileno, para luego examinar, como objeto principal de esta investigación, los límites y estrictos requisitos a los que debe someterse la admisibilidad de la tutela de mera certeza y que permiten diferenciarla de la potestad no contenciosa y evitar su utilización con una finalidad meramente consultiva o de opinión o probatoria de hechos jurídicos, impropia de la función jurisdiccional.

Se abordarán, así, los cuatro principales requisitos que hacen procedente la declaración de mera certeza, comenzando por el estudio de aquello que puede constituir o ser objeto de un proceso meramente declarativo; la existencia de incertidumbre jurídica o falta de certeza prejudicial de los derechos o intereses legítimos de las partes; la existencia de un interés que justifique la necesidad de la tutela solicitada fundado en la existencia de riesgo de perjuicio y la inexistencia de otros medios procesales más adecuados para la tutela del derecho o interés, requisito que ha llevado a parte de la doctrina a sostener el carácter subsidiario de esta acción.

Para concluir, se analizarán algunas cuestiones y problemas procesales relevantes a que da lugar la acción meramente declarativa y que dicen relación,

${ }^{1}$ Que "ha permitido a la doctrina moderna la revisión y la construcción sobre nuevas bases de los conceptos más importantes del proceso (y) ha proporcionado los más decisivos argumentos para la demostración del principio de autonomía del derecho de acción". ChIOvenda (2016), pp. 38 y 39. 
principalmente, con los efectos de la sentencia de mera certeza que se dicte en el proceso y la forma de solicitar y oponerse a su cumplimiento.

\title{
2. Origen y reconocimiento de la tutela meramente declarativa como parte esencial de la función jurisdiccional
}

\author{
El origen de la tutela declarativa -a la vez acción y sentencia-, se remonta \\ al propio Derecho romano ${ }^{2}$ y ha venido siendo reconocida por la mayoría de
}

2 Se trata de las denominadas formulae praejudiciales, actiones praejudiciales o praejiudicia del
Derecho romano, fórmulas cuya finalidad era la simple constatación acerca de la existencia de un
supuesto jurídico o de hecho del que dependía la decisión de un litigio en curso o futuro y que
constituyen el precedente de la acción meramente declarativa y la de jactancia o de difamación.
Sobre el origen y antecedentes de estas acciones en Roma, ver De SAVIGNY (1879), pp. 51 y ss.; MurGa
(1983), pp. 182 y ss. y BorCHARD (2016), pp. 93 y ss., quien sostiene que cuando la declaración "era
incidental o previa a la ejecución ordinaria, se la denominó praejudicium (y) tan eficaz fue ese
procedimiento que terminó por hacerse extensivo a otras acciones independientes a través de las
cuales no se pretendía una sentencia de ejecución (condemnatio). Entonces se las denominó actiones
praejudiciales recibiendo por tanto la jerarquía de actiones que con anterioridad no se les reconocía".
Para ChIOvenda (2016), p. 39 , la importancia jurídico-social de esta acción radica "(..) en la segu-
ridad que la misma permite dar a las relaciones jurídicas entre los hombres, y en el hecho de que
ella previene e impide los actos ilegítimos en lugar de afectarlos después de ocurrido con el peso
de graves sanciones. Ampliamente aplicada por los Romanos (praeiudicia), transformada durante el
derecho intermedio en la modalidad ruda y bárbara de los procesos provocatorios (ex legge diffa-
mari y ex lege si contendant), la acción meramente declarativa ha surgido en todos los derechos
modernos, ya en virtud de expresas normas de ley, ya por obra de la doctrina o la jurisprudencia; y
presentan particular interés las discusiones de que la misma es actualmente en la doctrina y en la jurisprudencia de los Estados Unidos".

En la misma línea, para Rivero (2016), pp. 15, 16 y 21, pie de página № 16 y 28, se trataba de "(..) verdaderos juicios preparatorios destinados a dilucidar un punto o cuestión específica. En cuanto a su contenido, se distinguían principalmente dos clases. Por un lado, las denominadas cuestiones de estado tendientes a determinar si una persona es o no liberto respecto de otra (praejudicium de libetinitate $o$ an libertus sit $(G ., 4,44)$; si es o no hija de otra (praejudicium an filius o de partu agnosendo $(C ., 8,46,9)$ y, finalmente, las destinadas a determinar la condición de esclavo (praejudicium an liber sit $(I .4,6,13)(\ldots)$. De otro, estaban las fórmulas relativas a las causas pecuniarias o patrimoniales destinadas a precisar la cuantía de la dote (praejudicium quanta dos sit (G. 4, 44) o la cuantía del objeto litigioso (praejudicium an res mayor (Paulo 5, 9, 1) y la destinada a examinar la declaración del acreedor acerca de la cuantía de la deuda y el número de avalistas que la garantizan (praejudicium sit ex lege Cicereiae $(G ., 3,123)$. (...) En lo que respecta a la naturaleza y eficacia de estas acciones, no existe consenso en la doctrina romanista. Para algunos autores, las actiones praejudiciales no tienen el carácter de acciones propiamente tales, sino que se trata de cuestiones meramente incidentales que carecen de autonomía procesal (...) Para otra parte de la doctrina, por el contrario, gozan de autonomía e independencia respecto de la cuestión principal, gozando la sentencia que se dicte de eficacia absoluta o erga omnes. (...) Con todo, para la doctrina lo cierto es que estas acciones posteriormente evolucionaron adquiriendo carácter procesal autónomo constituyendo la base de la actual demanda de declaración incidental regulada en el Derecho italiano". En el caso de España, para la doctrina la importancia de estas acciones subsiste hasta nuestros días, constituyendo el precedente y punto de partida de las acciones meramente declarativas y la acción de jactancia. Al respecto, se sostiene que es "manifiesta la finalidad preventiva de tales acciones en 
los ordenamientos europeos y los sistemas angloamericanos, en una primera etapa gracias a la labor de la doctrina y la jurisprudencia, para luego alcanzar consagración positiva en las propias leyes de enjuiciamiento.

Los sistemas del common law han sido, sin duda, claros precursores en este tema admitiendo la procedencia de la mera declaración de forma amplia y con carácter principal $-y$ no meramente subsidiario- ${ }^{3}$, en razón, primordialmente, del valor preventivo que se reconoce a este tipo de tutela (declaratory judgments) ${ }^{4}$. Su utilización práctica, así, es de gran frecuencia, aunque con una delimitación estricta y clara de sus presupuestos y límites en orden a evitar la utilización indebida de los tribunales de justicia como meros órganos consultivos o de opinión (advisory opinions) o para la resolución de cuestiones puramente académicas (moot cases) o de hechos ${ }^{5}$.

De igual forma, los sistemas europeo-continentales han reconocido la importancia, necesidad y procedencia de la tutela de mera declaración, pero acentuando su carácter subsidiario a la tutela de condena o constitutiva -cuya posibilidad de interposición constituye un límite a la tutela de mera declaración cuando el actor está en posición de ejercer una acción más incisiva-, carácter que, con algunos matices, ha sido sostenido por parte importante de la doctrina alemana, italiana y española.

cuanto tratan de suprimir y evitar el estado o situación de incertidumbre, inseguridad y riesgo de los derechos y, por tales razones, han dado base para que nuestra doctrina y jurisprudencia reconozcan, admitan y declaren su conveniencia efectiva, su utilidad práctica y su vigencia jurídica". Muñoz (1984), pp. 55 y 56. Más información sobre esta materia en RECCHIONI (1999), pp. 16 y ss. y SAMPER (2000).

${ }^{3}$ Tanto en Estados Unidos como en el Reino Unido, es posible encontrar un reconocimiento de la tutela meramente declarativa a nivel de fuentes estatutarias y jurisprudenciales. En Estados Unidos la acción declarativa se encuentra recogida en las Federal Rules of Civil Procedure (Rule 57), mientras que en el derecho inglés se encuentra consagrada -con idéntica denominación- en la regla 40.20 del Civil Procedure Rules de 1998. Asimismo, es posible encontrarlo en la jurisprudencia de la Cámara de los Lords (hoy Corte Suprema del Reino Unido) en el caso Ainsbury v Millington, House of Lords, 12 de marzo de 1987.

${ }^{4}$ ZuCKerman (2013), p. 1061. Conforme señala este autor, se entiende como declaratory judgment a una declaración obligatoria y vinculante de la Corte concerniente al estado jurídico de un asunto sometido a su conocimiento, normalmente señalando o estatuyendo la posición jurídico-legal de una cuestión en disputa. Respecto a la evolución y reconocimiento de la acción de certeza en los sistemas procesales europeos y angloamericanos, ver ampliamente BORCHARD (2016), pp. 69-125 y ROSEMBERG (2016), pp. 41-54.

${ }^{5}$ Así, por ejemplo, se llevará a cabo un declaratory judgment sólo cuando exista un asunto o situación (issue) pendiente sobre el cual se debe resolver, debiendo esa declaración tener alguna consecuencia práctica para las partes o terceros en concreto, descartándose las meras preguntas hipotéticas. ZUCKERMAN (2013), p. 1061. 
En esta línea, ciertamente han sido la dogmática y la ley alemanas (art. §256 $\mathrm{ZPO})^{6}$ las que han aportado mayormente al desarrollo de la tutela de mera declaración, perfilando sus requisitos y límites fundamentales, estudios y reconocimiento que han sido secundados en Italia, donde el principal precursor ha sido Chiovenda ${ }^{7}$.

Destaca, asimismo, el caso español en cuyo sistema procesal la tutela meramente declarativa ha tenido un reconocimiento positivo tardío en la Ley de Enjuiciamiento Civil de 2000 (LECiv 2000) ${ }^{8}$, no obstante lo cual, y pese a haber existido un período de confusión y desconfianza al respecto, su procedencia fue y ha sido ampliamente reconocida por la doctrina y por la jurisprudencia del Tribunal Supremo (TS) y del propio Tribunal Constitucional español (TCE) como parte esencial del derecho a la tutela judicial efectiva encuadrado en el art. 24 de la Constitución Española (CE), si bien como instrumento más bien de carácter excepcional y no de aplicación general ${ }^{9}$.

En definitiva, aun a falta de reconocimiento legal expreso de la acción de mera declaración, tanto la jurisprudencia como la doctrina comparada han reconocido su procedencia incluyéndola -junto con las acciones constitutivas y de condena- dentro de la tipología tradicional de la tutela declarativa para la protección de los derechos e intereses legítimos de las personas ${ }^{10}$.

En esta línea, y si bien, por regla general, se ha entendido que la tutela jurisdiccional del derecho privado obedece al principio de legalidad, para la doctrina "el postulado de la configuración normativa de las modalidades de tutela jurisdiccional no puede entenderse en la forma simplista de exigir que aquéllas tengan respaldo en textos legales que las regulen con exacta previsión legal y de modo sistemático. En defecto de una regulación técnicamente más

\footnotetext{
${ }^{6}$ Conforme a dicho precepto legal "Se puede proponer acción para la mera declaración de la existencia o de la no existencia de una relación jurídica, para el reconocimiento de una escritura o para la mera declaración de falsedad de la misma, cuando el actor tiene un interés jurídico en que la relación jurídica, la autenticidad o la falsedad de la escritura sea declarada inmediatamente por decisión judicial". Sobre el contenido y aplicación de esta norma, ver ampliamente el comentario Rотн (2013) al artículo §256 de la ZPO. De forma similar, la acción declarativa ha sido regulada en la Ordenanza Procesal austriaca (art. §228).

7 Chiovenda (2016), pp. 1-39. En la misma línea, Carnelutti (1943), pp. 17-22.

${ }^{8} \mathrm{Al}$ efecto, el art. 5.1 establece que "Se podrá pretender de los tribunales la condena a determinada prestación, la declaración de la existencia de derechos y de situaciones jurídicas, la constitución, modificación o extinción de estas últimas, la ejecución, la adopción de medidas cautelares y cualquier otra clase de tutela que esté expresamente prevista por la ley".

${ }_{9}^{9}$ Sobre la evolución, desarrollo y reconocimiento de este tipo de tutela en España, ver ampliamente CALDERÓn (2008).

10 Por todos, ver Ortells (2016), pp. 58-64; Gimeno (2004), pp. 212-218 y Armenta (2016), pp. 115-124.
} 
perfecta, la norma reguladora puede ser extraída aplicando los criterios de interpretación y los métodos de investigación integradora al material normativo de toda clase (disposiciones legales, principios jurídicos) ${ }^{\prime \prime 1}$.

En Chile la situación no ha sido diferente. Si bien nuestras leyes procesales no contemplan ni distinguen expresamente las diferentes formas de tutela, ni menos aún la meramente declarativa como categoría diferenciada, ha sido la propia jurisprudencia, secundada por la doctrina, la que ha venido desarrollando y delimitando el contenido y procedencia de la acción de mera declaración como una "función jurisdiccional propia de los tribunales creados por la ley y más concretamente de los tribunales ordinarios, pues a éstos les corresponde conocer de los asuntos civiles contenciosos que la ley no entrega a determinado tribunal especial"12.

Sobre la materia, y entendiendo que la procedencia de este tipo de tutela encuentra fundamento:

“(...) en los arts. 24 del Código Civil y 170 N 5 del de Procedimiento Civil, en relación al $N^{\circ} 9$ del Auto Acordado de la Corte Suprema sobre Forma de las Sentencias, al espíritu general de la legislación y a la equidad natural"

se ha sostenido por los tribunales de justicia que:

“(...) nuestra legislación no repulsa las acciones de mera declaración; antes bien, son de ordinaria ocurrencia las que, con sujeción a ella, se intentan exitosamente: tales, por ejemplo, las que se deduce para alzar una hipoteca que cauciona un crédito extinguido, las que se promueve para obtener el reconocimiento del dominio a virtud de la prescripción adquisitiva, la que se intenta para lograr la declaración de simulación relativa, la que se interpone para que se fijen los límites que separan a un predio de los colindantes, etc.; y estos aparte que hay casos, como el de jactancia y el de inaplicabilidad de preceptos contrarios a la Constitución, que están expresamente considerados por la ley"13,

existiendo numerosos fallos en los que se han ido delimitando los requisitos y procedencia de este tipo de pretensiones.

\footnotetext{
11 Ortells (2016), p. 53.

12 Sentencia Corte Suprema ( $\sin N^{\circ}$ de rol), de 13 de noviembre de 1985.

13 Sentencia $4^{\circ}$ Juzgado Civil de Santiago, de 23 de marzo de 1963. Se trata del famoso caso Otero con Falabella en el que se interpuso una acción meramente declarativa por uno de los cónyuges solicitando al juez terminar con la situación de inseguridad jurídica que afectaba a las partes y terceros, por no haberse inscrito el pacto de separación total de bienes celebrado por los cónyuges, sentencia que no fue apelada.
} 
En la misma línea, y especialmente a propósito de la denominada acción de jactancia -que tradicionalmente ha sido vista como antecedente directo de la acción de mera declaración- y de las acciones protectoras (innominadas) del dominio y los derechos reales ${ }^{14}$, la doctrina ha aportado al desarrollo dogmático de la acción de certeza y la necesidad de su consagración, existiendo en la actualidad consenso en cuanto a su importancia y plena procedencia en el proceso civil ${ }^{15}$, e incluso en materias tan disímiles como el derecho tributario $^{16}$, el amparo económico ${ }^{17}$ y el derecho administrativo, área esta última donde ha tenido gran aplicación práctica como instrumento para hacer frente a la Administración del Estado ${ }^{18}$.

Recientemente, recogiendo esta realidad y evolución jurisprudencial y doctrinaria, de lege ferenda, cabe destacar la regulación contenida en el Proyecto de Nuevo Código Procesal Civil, actualmente en discusión en el Parlamento (Boletín No 8.197-07), el que por primera vez en el sistema procesal chileno moderniza la nomenclatura en torno a la tipología de pretensiones, reconociendo, a propósito de la ejecución provisional de las sentencias (arts. 234 y ss.), la sentencia meramente declarativa como categoría procesal autónoma ${ }^{19}$.

Así, tanto a nivel nacional como comparado, y de forma prácticamente unánime, la tutela meramente declarativa es concebida como una función primordial de la jurisdicción y presupuesto esencial de la tutela de condena y de ejecución en orden a dar certeza a los derechos de las partes de forma previa o prejudicial a la obtención de una condena o ejecución entendiéndose, con razón, que antes que la tutela o actividad jurisdiccional de ejecución, la tutela judicial del Derecho privado: "(...) requiere inicialmente de un pronunciamiento jurisdiccional en el que, tras las alegaciones y las pruebas

\footnotetext{
14 Peñallillo (2007); Lathrop (2011), pp. 3-24 y Larroucau (2015), pp. 109-160; Atria (2004), pp. 21 56 y ATRIA (2017), pp. 147-212, quien, con todo, centra su examen sólo en la acción reivindicatoria.

15 Romero (2007), pp. 33-38.

16 UGarte y Alonso (2011), pp. 337-350.

17 Alvear (2013), pp. 167-220.

${ }^{18}$ En esta área, ha sido principalmente el Prof. Eduardo Soto Kloss quien ha profundizado en este tema, considerando la acción de mera certeza como uno de los principales y más útiles mecanismos procesales para hacer frente a la Administración de Estado. Sobre la materia, ver ampliamente Sото (2005), pр. 559-566; Sото (2012a), pp. 753-758; Sото (2012b), pp. 13-23, Sото (2017a), pp. 503513 у Sото (2017b), pp. 94-114.

19 En consonancia con la naturaleza de este tipo de sentencias que, como se verá, solo son objeto de cumplimiento pero no de ejecución, el proyecto regula la aplicación de la ejecución provisional respecto de las sentencias de condena, excluyendo expresamente las sentencias declarativas así como las constitutivas de la posibilidad de ejecución provisional (art. 236, № 1).
} 
desarrolladas contradictoriamente en el proceso, se establezca, con la necesaria certeza, si quien pide la tutela tiene derecho a ella"20.

Conforme a ello, en términos generales y con más o menos elementos, la doctrina ha entendido la pretensión y sentencia de mera certeza, la que puede ser positiva o negativa, como aquella:

“(...) figura general de acción y de sentencia con la que el actor que la propone o la invoca tiende exclusivamente a procurarse la certeza jurídica, frente a un estado de falta de certeza que le es perjudicial, pidiendo a tal objeto que se declare existente un derecho suyo o inexistente el derecho ajeno, con independencia de la efectiva realización, de la condena, de la ejecución forzada" ${ }^{21}$.

En la misma línea, para la doctrina española las acciones meramente declarativas: "(...) son aquellas en las que el demandante solicita una declaración del juez sobre la existencia o inexistencia de un determinado derecho, relación jurídica o situación jurídica que son inciertas" ${ }^{\prime 22}$ radicando su utilidad práctica "en la certeza jurídica que genera tal sentencia sobre las relaciones concretas sobre las que hace declaración. Si hubiera futuros procesos a los que alcanzara la cosa juzgada de la sentencia, lo resuelto en ellas sería vinculante, lo cual normalmente inducirá a las partes a evitar esos futuros procesos, no dando causa para los mismos"23.

En definitiva, la acción de mera certeza es entendida como aquella en la que se persigue que el juez declare o se pronuncie acerca de la existencia o inexistencia, alcance o modalidad de un determinado derecho, relación o situación jurídica sin que se imponga al demandado condena alguna ni modificación de una situación jurídica determinada ${ }^{24}$, logrando con ello "que se ponga fin a un estado de incertidumbre jurídica" 25 .

Despejado en la forma antes descrita el origen, contenido esencial y pleno reconocimiento de la acción de mera certeza tanto en el derecho comparado como en el propio sistema chileno, la doctrina y la jurisprudencia se han

${ }^{20}$ Ortells (2016), p. 54.

${ }^{21}$ Chiovenda (2016), pp. 38.

22 Robles (2013), p. 273.

23 Ortells (2016), p. 57.

${ }^{24}$ Enderle (1992), p. 41. Como señala la doctrina, esta característica distintiva de la acción de mera declaración viene recogida de su regulación en Escocia donde los comentaristas definen la acción declarativa como aquella "en la que se solicita que se declare el derecho del actor, pero 'sin deducirse ninguna exigencia contra el demandado'". BORCHARD (2016), p. 106.

25 Romero (2007), p. 33. 
encargado de afirmar, con todo, la existencia de estrictos requisitos a los que debe someterse la admisibilidad de este tipo de acción o tutela.

En efecto, como se verá en las páginas siguientes, la principal dificultad que suscita este tipo de pretensión es precisamente la determinación de los límites y los requisitos que debe cumplir la tutela de mera declaración para su admisibilidad por parte del tribunal y que permiten diferenciarla del uso de facultades meramente consultivas o no contenciosas que resultan impropias a la función jurisdiccional que están Ilamados a cumplir los órganos jurisdiccionales.

Al efecto, la doctrina es coincidente en señalar la concurrencia de, a lo menos, cuatro requisitos esenciales e inescindibles a la naturaleza propia de este tipo de tutela judicial: (1) el objeto de declaración solo puede ser un derecho, relación o situación jurídica concreto y actual susceptible de constituir objeto de un proceso autónomo; (2) la existencia de incertidumbre jurídica o falta de certeza prejudicial sobre la inexistencia, alcance o modalidad del derecho, situación o relación jurídica determinada; (3) la existencia de un interés que justifique la necesidad de la tutela solicitada fundado en la existencia de riesgo de perjuicio solo reparable con la declaración del juez en la sentencia y, (4) la inexistencia de otros medios o acciones procesales más adecuados para la tutela del derecho o interés y el carácter subsidiario de la acción de certeza.

A continuación, examinaremos breve, pero detalladamente, cada uno de los requisitos antes descritos y la forma como han sido recogidos y entendidos por la doctrina y aplicados por la jurisprudencia en el ordenamiento chileno.

\section{Requisitos de procedencia de la acción meramente declarativa o de mera certeza}

\subsection{Primer requisito: el objeto de la acción de mera certeza. Cuestión susceptible de ser objeto de un proceso autónomo e independiente. La mera certeza y la simple declaración de existencia o inexistencia de hechos}

La primera cuestión que resulta indispensable despejar para determinar la procedencia de la tutela de mera declaración es su objeto, esto es, aquello que es susceptible de ser solicitado y declarado por el juez en su sentencia.

Al efecto, es communis opinio que el objeto de la tutela de mera certeza solo puede ser un derecho, relación o situación jurídica, único tipo de cuestiones que pueden ser objeto de un proceso autónomo e independiente y respecto de las cuales se puede producir la cosa juzgada de la sentencia.

Junto a lo anterior, la doctrina exige, además, que el derecho, situación o relación jurídica objeto de la declaración sea concreto, actual y presente, 
no abstracto, teórico ni debe tratarse de relaciones futuras. Puede tratarse de derechos o situaciones pasadas, pero siempre y cuando produzcan aun efectos en el presente. Finalmente, y lo más importante, es que el derecho, relación o situación debe ser dudoso o controvertido por las partes ${ }^{26}$.

En esta línea, el Prof. Romero sostiene que la:

“(...) protección jurisdiccional a que tiende la acción declarativa se caracteriza por: $1^{\circ}$ ) Se encamina exclusivamente a la constatación judicial de la existencia o inexistencia de una relación o situación jurídica; $\left.2^{\circ}\right)$ La declaración de certeza no puede recaer sobre situaciones hipotéticas o futuras, sino sobre una controversia actual"27.

Dentro de las cuestiones de derecho que hacen procedente la acción de mera declaración, la doctrina es coincidente en admitir como parte de ella, asimismo, la solicitud al juez para que determine la correcta interpretación o aplicación de la norma o estatuto jurídico que corresponde a una determinada relación o situación jurídica, eliminando de esta forma el estado de incertidumbre jurídica que hubiere podido suscitarse frente a la duda o controversia en torno a su aplicación.

Lo importante, con todo, es que dicha declaración no puede pedirse en abstracto sino con relación a una determinada persona y relación jurídica, de manera tal que la declaración del derecho constituye realmente una premisa y no el objeto de la declaración de certeza ${ }^{28}$.

En Chile, como es posible advertir, este es el uso más frecuente que se ha dado a la acción de mera certeza, especialmente en el ámbito de las controversias entre particulares y la Administración del Estado o incluso entre entes públicos. Casos emblemáticos han sido resueltos por esta vía a efectos de determinar, por ejemplo, cuál es el derecho o estatuto jurídico aplicable a un determinado ente estatal o empresa del Estado, o si este es o no fiscalizable por la Contraloría General de la República, o bien si un determinado tributo es o no aplicable o exigible a un contribuyente ${ }^{29}$.

\footnotetext{
${ }^{26}$ Por todos, Chiovenda (2016), pp. 8 y ss.

27 Romero (2007), p. 34.

${ }^{28}$ Chiovenda (2016), p. 9.

${ }^{29}$ Entre estos casos, se encuentra el de TVN vs. Fisco-Contraloría General de la República, donde, a través de una acción de mera certeza se resolvió acerca del estatuto jurídico aplicable al canal público y que este no es fiscalizable por la Contraloría. Al respecto, se sostuvo que "Si se acoge la tesis de Contraloría y se margina a los tribunales existentes de la posibilidad de conocer de una acción por medio de la cual se llegue a decidir si la interpretación efectuada por el organismo contralor es o no la jurídicamente correcta se concedería un poder irrestricto a este último en referencia, sucediendo que una decisión jurídicamente equivocada o eventualmente arbitraria del mismo no
} 
Por regla general, por tanto, y salvo el caso excepcional de la declaración de autenticidad o falsedad de un documento o instrumento, reconocida en el derecho francés, alemán e italiano -y también aceptada en el ordenamiento chileno-, a nivel de doctrina y jurisprudencia existe amplio consenso en cuanto a que la simple declaración de existencia o inexistencia de hechos, aun cuando se trate de hechos jurídicamente relevantes, no puede ser objeto de la acción de mera certeza ${ }^{30}$.

Lo anterior forma parte de un principio general aceptado por la doctrina y aplicable, a nuestro juicio, tanto a la tutela de mera declaración como a la constitutiva y de condena, conforme al cual los hechos, por sí mismos considerados, no son ni pueden ser objeto de tutela judicial de ningún tipo,

tendría posibilidad de solución jurisdiccional. No es el parecer sin embargo de este sentenciador que se admita ni aun excepcionalmente dentro de nuestro sistema jurídico que haya conflictos que queden marginados de la posibilidad de ser resueltos, sino que debe estimarse que frente a los amplios términos de los arts. 73 de la Constitución Política de la República y $5^{\circ}$ del Código Orgánico de Tribunales cualquier deficiencia queda cubierta, no pudiendo ser obstáculo para la decisión de un conflicto como el de autos la circunstancia de que aún no hayan sido creados Tribunales Administrativos que hayan de conocer de él en forma especializada". Sentencia $26^{\circ}$ Juzgado Civil de Santiago, rol N ${ }^{\circ}$ C-10-94, de 27 de julio de 1995 (c. $4^{\circ}$ ), confirmada por Sentencia Corte de Apelaciones de Santiago, rol No 4882-95, de 21 de septiembre de 1998.

De forma similar, y frente a la una demanda de certeza deducida por un particular frente a la duda sobre la validez del pago realizado de un tributo, la Corte ha sostenido que "(...) al existir una verdadera contienda entre las partes en cuanto a la interpretación y alcance de una norma legal de carácter tributario, resulta plenamente válida la intervención del tribunal a fin de dar certeza y seguridad en esta relación jurídica y justamente para terminar con esa incertidumbre, el juez es Ilamado a resolver el conflicto". Sentencia Corte de Apelaciones de Santiago, de 30 de diciembre de 1983, p. 124. Sobre estas acciones, ver ampliamente Sото (2017a), pp. 503-514 у Sото (2017b), pp. 94-114.

Sobre la materia, y en un reciente fallo dictado a propósito de la acción de mera certeza presentada por más de 800 funcionarios de la Dirección de Aeronáutica Civil ante el $29^{\circ}$ Juzgado Civil de Santiago para que se declarara aplicable a estos funcionarios el estatuto de seguridad social de las Fuerzas Armadas y no el D.L. № 3.500 y la contienda de competencia deducida por esta razón por el Contralor General de la República, el Tribunal Constitucional chileno, fallando en favor de la Contraloría, ha establecido un importante límite a la procedencia de la acción de mera certeza. Al efecto, y estableciendo como regla de principio que no existen actos estatales exentos de revisión jurisdiccional, sostiene el TC que "dicha acción de creación jurisprudencial no alcanza la modificación o exclusión de normas legales vigentes, cuestión que (...) excede de las competencias jurisdiccionales y se inmiscuye derechamente en el ámbito reservado al legislador, sin perjuicio de afectar también las facultades interpretativas de tales normas por parte de la Contraloría". En definitiva, para el TC, mediante una acción de mera certeza los tribunales no pueden entrar a interpretar de forma abstracta, genérica y retroactiva los textos constitucionales y legales que gobiernan la materia. Sentencia Tribunal Constitucional, rol №3283-16 CCO, de 18 de enero de 2017. En sentido similar, en marzo de 2018, por 16 votos a favor y 12 en contra, el Senado de la República falló en favor de la Contraloría General de la República la contienda suscitada por este mismo caso frente a la Corte Suprema.

30 En esta línea, Chiovenda (2016), p. 10; Rosenberg (2016), p. 50 y Goldschmidt (2016), pp. 283 y 284. 
ni pueden ser planteados como objeto principal de un proceso autónomo e independiente con eficacia de cosa juzgada.

En palabras de Chiovenda:

"(...) los hechos jurídicos, que tienen importancia sólo en cuanto sirven a la formación y a la aplicación de una voluntad de ley, son declarados por el juez como premisa del silogismo que conduce a la declaración de esta voluntad; y por sí solos no pueden ser objeto principal de una declaración" $n^{31}$.

En la misma línea, para Wach:

"El fin del proceso es la finalidad de protección del derecho, no la finalidad de prueba ni la finalidad de la declaración de hechos" ${ }^{\prime \prime 32}$.

Así, por ejemplo, ciertamente el proceso penal no está concebido para solicitar al juez penal la declaración de existencia o inexistencia de un determinado hecho punible o del delito - un accidente o asesinato- sino para anudar al mismo las consecuencias jurídico-penales previstas por el legislador y aplicar una pena al autor, haciendo efectivo el ius puniendi estatal.

En esta línea, para la doctrina española, a propósito de la acción civil ex delicto y la vinculación del juez civil a la sentencia penal, ha sostenido que por:

"(...) sí mismos, los hechos no son objeto de pronunciamiento judicial; no existe (...) una pretensión mero declarativa de la existencia o inexistencia de hechos. Aún menos en el contexto del proceso penal que no puede entenderse preordenado a formular meras declaraciones ya de hechos, de derechos o situaciones jurídicas, sino a determinar si procede aplicar o no el ius puniendi estatal".

Desde esta perspectiva, en la medida que

"sólo puede pasar en eficacia de cosa juzgada aquello que por sí mismo puede constituir un objeto procesal autónomo (...) la declaración de existencia o no de los hechos (...) sólo adquirirán el valor de cosa juzgada en la medida que se integren en una situación jurídica o de derecho' ${ }^{133}$.

De la misma forma, en lo que respecta al proceso civil, tal como señala Chiovenda no puede ser objeto de este tipo de procesos la simple declaración de:

31 Chiovenda (2016), p. 422.

32 WaCH (1962), pp. 95 y 96.

33 JUAN (2004), pp. 442 y 443. 
"(...) que fue concluido un contrato, sino de que existe un contrato válido; ni que Ticio ha cometido un delito, sino que él es responsable de los daños; ni que una mercadería es defectuosa, sino que se tiene derecho a devolverla; ni que Cayo ha sido admitido en una sociedad, sino que es miembro de esa sociedad; ni que ha existido cohabitación entre Mevia y Simpronio, sino que Simpronio es padre natural"34.

De esta forma, los tribunales solo fijan y se pronuncian respecto de hechos en la medida que éstos constituyan un presupuesto para la aplicación de una norma jurídica en el contexto de una solicitud de tutela de derechos e intereses legítimos de las partes, anudando a ellos las consecuencias jurídicas previstas por el legislador, pero no pueden ser objeto principal de un proceso civil o penal autónomo ni quedan, por sí mismos, cubiertos por la eficacia de la cosa juzgada.

En definitiva, tal como señala la doctrina:

"(...) los hechos, por sí mismos, o dicho en otros términos, la determinación de su existencia o inexistencia, no puede ser objeto de un proceso autónomo o independiente sino en la medida que formen parte del contenido fáctico o presupuesto de hecho de una norma jurídica que debe ser probado en el proceso a efectos de que el juez pueda anudar las consecuencias jurídicas previstas por la misma" ${ }^{35}$.

$\mathrm{Y}$ aun en este caso, a menos que se propugne la más estricta doctrina material de la cosa juzgada, tal como señala De la Oliva, los hechos que se ventilan en un proceso por sí mismos considerados no son vinculantes ni quedan cubiertos por la cosa juzgada sino en la medida que forman parte de una sentencia con dicha eficacia. A juicio de este autor, no siendo posible negar: "(...) la relevancia de los hechos en cuanto a la cosa juzgada y a la delimitación de su ámbito porque es a todas luces imposible prescindir de ellos para determinar qué es excluido por una sentencia firme sobre un objeto procesal (función negativa o excluyente de la cosa juzgada) y hasta dónde alcanza la fuerza vinculante de una sentencia dotada de autoridad de cosa juzgada (función positiva o prejudicial)", cosa distinta es si dichos hechos por la sola virtualidad de unirse inescindiblemente a juicios jurídicos, poseen en sí mismos fuerza de cosa juzgada.

En definitiva, concluye:

${ }^{34}$ Chiovenda (2016), p. 10.

35 Rivero (2016), pp. 50 y ss. 
"(...) que los juicios sobre hechos, aunque contenidos en sentencias firmes, no son vinculantes en sí mismos o aisladamente considerados. Han de ser respetados, pero no por la fuerza vinculante ligada a ellos, sino en el marco de la cosa juzgada, en cuanto fundamento de una sentencia con eficacia prejudicial. En otros términos, cuando lo resuelto en una sentencia firme aparezca como antecedente lógico o como parte del objeto del proceso posterior" ${ }^{\prime \prime 3}$.

Como señalamos anteriormente, la única excepción a esta regla contemplada en el derecho francés, alemán e italiano la constituye la declaración acerca de la falsedad o autenticidad de un instrumento, permitiéndose que un hecho jurídico -la divergencia entre lo documentado y la realidad de lo acontecido $^{37}$ - sea declarado como objeto de un proceso autónomo y con eficacia de cosa juzgada.

Con todo, tal como señala la doctrina, esta excepción ha venido siendo cuestionada en Alemania esencialmente por la escasa utilización práctica que ha tenido, a diferencia de Italia y Francia donde tiene gran relevancia ${ }^{38}$. En España, por el contrario, no se permite la declaración de falsedad o autenticidad de los instrumentos en un proceso civil autónomo ni tampoco incidentalmente, sino solo mediante un proceso penal por delito de falsedad.

En el ordenamiento chileno, no existe una limitación de esta naturaleza en tanto, y particularmente en lo que respecta a los instrumentos públicos, se permite su impugnación en un proceso civil tanto por vía incidental como por vía principal ${ }^{39}$, así como en un proceso penal por alguno de los delitos de falsedad contemplados en el Código Penal.

${ }^{36}$ De la Oliva (2005), pp. 235, 236 y 246.

37 Ortells (2004), p. 1936.

${ }^{38}$ ChIOvenda (2016), pp. 7 y 8 . A juicio de la doctrina, el ordenamiento italiano utiliza una técnica jurídica que simboliza una mayor protección del valor probatorio legal de los documentos, en tanto contempla la posibilidad de obtener una declaración de la falsedad del documento mediante un proceso civil autónomo o a través de una cuestión incidental inserta dentro del propio proceso civil en el que el documento ha sido aportado. Confróntese Ortells (2004), p. 1937.

39 En esta línea, Maturana (1999), p. 37; Ducci (2010), pp. 415-418; Santa Cruz (2010), pp. 363-395; Casarino (2009), pp. 68 y 69; Rodrícuez (2010), p. 148 y Meneses (2017), pp. 510-516, difiriendo en si la impugnación por vía incidental puede realizarse o no por las tres causales de nulidad, falta de autenticidad y falta de veracidad o solo la falta de autenticidad. En esta línea, asimismo, Sentencia Corte Suprema, de 26 de marzo de 1966 (cs. $3^{\circ}$ y $4^{\circ}$ ).

Con todo, parte de la doctrina entiende que la impugnación de un instrumento público por vía incidental sólo puede realizarse por falta de autenticidad del instrumento. Tratándose de la impugnación por nulidad o simulación o falsedad ideológica del mismo, ésta debe hacerse por vía principal, a través de un juicio de lato conocimiento. Maturana (1999), p. 37. 
Sentado lo anterior, y por las razones apuntadas, un primer presupuesto esencial de la acción de mera certeza y en general de la tutela declarativa es la exclusión, como regla general, de la simple declaración de existencia o inexistencia de hechos como objeto de un proceso autónomo o independiente.

De forma similar, en nuestro concepto, cabe excluir del objeto de la declaración de mera certeza la simple aplicación de conceptos o definiciones contenidos en normas jurídicas:

“(...) los que nunca podrán revestir dicho carácter, pues, por sí mismos, no pueden constituir el objeto de un proceso independiente. (A) sí ocurre, por ejemplo, con la determinación de si una cosa es mueble o inmueble; divisible o indivisible; comerciable o incomerciable, etc.; o la determinación de la mayoría de edad de un sujeto o el carácter mercantil o civil de una sociedad, etc. (...). Se trata en definitiva de meros puntos prejudiciales cuyo sentido y alcance el juez debe verificar, con aplicación de las normas sustantivas que corresponda, en forma previa a la decisión del asunto principal"40.

La jurisprudencia chilena ha recogido ampliamente esta exigencia. Al efecto, en diversos fallos la Corte Suprema ha sostenido que la acción de mera certeza:

"(...) sólo puede tener por objeto la declaración de un derecho que una parte estima asistirle, para evitar o componer un litigio que le afecta o puede afectarle en el futuro, agotándose la jurisdicción del Tribunal en la mera declaración de certeza sin que pueda imponer una prestación a la contraria (...). En consecuencia, se trata de una situación de incertidumbre, que afecta a la agraviada, que la autoriza a exigir del órgano jurisdiccional-llamado precisamente a declarar con fuerza legal el derecho aplicable-, se le clarifique su esfera subjetiva, precisando su campo de acción y los límites que la afectan, pronunciamiento que únicamente podrá obtener mediante una acción declarativa de derechos, como ha sucedido en la especie ${ }^{\prime \prime 4}$.

En el mismo sentido, poniendo énfasis en la finalidad de esta acción, se sostiene que:

“(...) la acción declarativa de mera certeza corresponde a 'aquellas que tienen por objeto la pura declaración de la existencia de un derecho' y

\footnotetext{
40 Rivero (2016), pp. 50 y ss. Sobre la materia, Chiovenda (1936), pp. 422 y 423; Chiovenda (2000), pp. 734 y 735; Gómez (1947), p. 142; Ortells (2016), p. 636, y Reynal (2006), pp. 58 y 59.

${ }^{41}$ Sentencia Corte Suprema, rol No 6585-2007, de 28 de mayo de 2009.
} 
que 'no van más allá de esa declaración' (...), de lo que se desprende que su finalidad se limita solamente a superar un estado de incertidumbre que no tenga otro medio de solución que el de un fallo judicial"42.

Siguiendo esta línea, la jurisprudencia ha rechazado demandas de mera certeza precisamente:

“(...) por no configurarse en la especie los requisitos para intentar una sentencia de mera certeza de un derecho, sino que de hechos como lo ha alegado el Fisco". Al calificar la acción, los "establecieron como una circunstancia fáctica la de que en la especie no se persigue declarar la mera certeza de un derecho, sino que de establecer hechos, para precaver una posible caducidad de la concesión de que goza la demandante, premuniéndose de tal manera de un verdadero paraguas jurídico que podría esgrimir frente a la concreción de tal circunstancia".

En el caso en cuestión, la empresa pesquera demandante dedujo acción declarativa de mera certeza a fin de que se declarara que no ha incurrido en la causal de caducidad del art. 142 letra c) de la Ley de Pesca. Al efecto, la Corte consideró que la parte demandante pretende:

"(...) que se prive, por esta vía, de la posibilidad de caducar, en el futuro, la concesión, y ello sobre la base de la que constituye una innegable circunstancia de hecho, esto es, no haber realizado actividades relacionadas con dicha actividad durante un cierto período. Se trata, sin lugar a dudas, de una pretensión desmedida y que no corresponde a la finalidad que la propia jurisprudencia ha asignado a la acción de declaración de mera certeza (...) tal como fue decidido por los magistrados de la instancia, pues se ha solicitado declarar hechos y, adicionalmente ordenar a la autoridad que se abstenga, en el futuro, de hacer uso de sus facultades, lo que constituye una pretensión inadmisible ${ }^{\prime 43}$.

Siguiendo esta línea, en un reciente fallo a propósito del recurso de unificación de jurisprudencia en materia laboral, la Corte Suprema ha delimitado la naturaleza meramente declarativa de la sentencia laboral que se pronuncia sobre la existencia y validez de la relación jurídica laboral, sosteniendo que:

“(...) tanto la doctrina como la jurisprudencia, han distinguido dos grandes tipos de pretensiones que dan origen a igual naturaleza de sentencias: de cognición y ejecución, que por su parte pueden ser desestimatorias o estimatorias. Las primeras, por su parte, se dividen

${ }^{42}$ Sentencia Corte Suprema, rol № 7586-2015, de 16 de diciembre de 2015, c. $1^{\circ}$.

${ }^{43}$ Sentencia Corte Suprema, rol No $3594-2004$, de 26 de enero de 2005, cs. $18^{\circ}, 21^{\circ}$ y $31^{\circ}$. 
en declarativas, constitutivas y de condena. La sentencia definitiva declarativa estimatoria civil es aquella por la cual el tribunal, estimando fundada la pretensión extraprocesal, declara acerca de la existencia o inexistencia (según sea lo pretendido) de una situación jurídica, estas pretensiones (y sentencias) tienen como especial característica que basta una declaración del tribunal para que sean satisfechas, sólo se limitará a declarar certeza sobre un estado o situación determinada, tiene su origen en el artículo 256 de la ordenanza procesal alemana de 1877 que dispuso 'Se podrá demandar la declaración de existencia o inexistencia de una relación jurídica o el reconocimiento de la autenticidad o la declaración de falsedad de un documento, si el demandante tiene un interés jurídico en que la relación jurídica o la autenticidad o la falsedad de un documento sea declarada inmediatamente por resolución judicial', sin perjuicio de encontrar su antecedente en las instituciones romanas de las fórmulas prejudiciales, conforme lo enseñan Scialoia, Alsina y Chiovenda" ${ }^{\prime 4}$.

Por último, en un fallo que no deja de ser controvertido, la jurisprudencia ha sostenido la viabilidad de solicitar por vía de acción la declaración de nulidad de un determinado acto o contrato, pero no su declaración de inexistencia como objeto principal de un proceso, imponiendo con ello, una clara restricción a la acción de mera certeza.

Al efecto, y entendiendo que la tesis de la inexistencia del acto jurídico es ajena a nuestro Derecho y que el Código Civil sólo establece la nulidad como sanción de ineficacia, carece de fundamento la petición en orden a declarar la inexistencia de un acto jurídico, pretensión que sólo puede ser alegada por vía de excepción pero no como acción.

Comentando el fallo en cuestión, para la doctrina esta sentencia da cuenta de que la inexistencia es un concepto que

"transita por el terreno de lo puramente fáctico, mientras que la nulidad sí es un concepto propiamente jurídico. Así, el conflicto jurídico solo se planteará cuando una parte alegue acerca de supuestas obligaciones emanadas de un acto que ella considera existente, siendo al demandado a quien corresponderá alegar la falta de requisitos que la ley prescribe para la validez de dicho acto en atención a su naturaleza -inexistencia del acto, si se quiere-, mediante una excepción perentoria). Sostener que el demandante puede sustentar su acción en

\footnotetext{
${ }^{44}$ Sentencia Corte Suprema, rol No 28657, de 17 de noviembre de 2016 y Sentencia Corte Suprema, rol No 8318-2014, de 3 de marzo de 2015.
} 
la falta de existencia del acto, implicaría partir del supuesto de postular 'la nada' como causa de pedir" 45 .

En definitiva, siguiendo lo expuesto, resulta claro que a través de una acción de mera certeza no es posible pretender la simple declaración de certeza de la existencia o inexistencia de hechos constitutivos, impeditivos, invalidativos, modificativos o extintivos sino solo en la medida que éstos constituyan un presupuesto para la aplicación de una norma jurídica en el contexto de una solicitud de tutela de derechos e intereses legítimos de las partes, no pudiendo utilizar este tipo de tutela jurisdiccional con una finalidad meramente consultiva y/o probatoria de hechos jurídicos.

\subsection{Segundo requisito: falta de certeza prejudicial o incertidumbre jurídica respecto de los derechos, relaciones o situaciones jurídicas de las partes. La función preventiva y de certeza prejudicial de la acción de mera declaración}

Con escasos matices, la doctrina es coincidente en sostener como fundamento y finalidad de la acción y sentencia meramente declarativa su función esencialmente preventiva pero, también, y principalmente, de certeza o fijeza de los derechos de las partes frente a situaciones de incertidumbre, duda o controversia sobre los mismos, función propia, por lo demás, de toda actividad jurisdiccional.

En este sentido, como se ha señalado anteriormente, la tutela declarativa no viene a constituir sino un presupuesto de la propia tutela de condena, así como de la ejecución, pues previo a condenar o ejecutar a alguna de las partes, es indispensable que exista, primeramente, certeza acerca de la existencia, inexistencia, contenido y/o titularidad del derecho, relación o situación jurídica objeto del juicio, siempre que sobre éstas exista controversia entre las partes. Tal como señala Chiovenda, en definitiva, la tutela declarativa, lato sensu, comprende toda la masa de las sentencias sobre demandas de condena que rechazan la demanda del actor declarando la inexistencia del derecho hecho valer en juicio ${ }^{46}$.

Siguiendo lo anterior, y como función propia de la potestad jurisdiccional, en nuestro concepto y antes que la función preventiva, la primera finalidad o función que está Ilamada a cumplir la tutela meramente declarativa es la de fijeza o certeza prejudicial de los derechos o relaciones jurídicas que

\footnotetext{
${ }^{45}$ WALKER (2015), p. 262. En la sentencia comentada, a juicio del tribunal "el acto inexistente, en efecto, equivale a la nada, y por lo tanto, no es posible que la nada pueda ser objeto de una acción $y$, por lo tanto, tampoco puede constituir materia de un juicio".

${ }^{46}$ Chiovenda (2016), p. 1.
} 
constituyen el presupuesto para el otorgamiento de la tutela de condena o constitutiva solicitada, cuando dichos derechos o relaciones resultan controvertidos en el mismo proceso o en juicios paralelos.

Esto es lo que la doctrina denomina cuestiones prejudiciales o prejudicialidad entendida, en un sentido amplio, como toda cuestión susceptible de ser objeto de un proceso autónomo que requiere ser resuelta en forma previa a la decisión sobre el fondo del asunto y de cuya decisión depende el otorgamiento o denegación de la tutela solicitada ${ }^{47}$. No se trata, como hemos visto, de un simple punto prejudicial controvertido en un proceso, sino de cuestiones susceptibles de constituir el objeto principal o el antecedente lógico de otros pleitos futuros ${ }^{48}$.

Al efecto y siguiendo la distinción formulada por Satta entre prejudicialidad lógica y técnica ${ }^{49}$, desde la perspectiva del objeto del proceso estas cuestiones prejudiciales pueden manifestarse de dos formas.

Por un lado -en lo que Satta denomina como prejudicialidad lógica- la cuestión coincide o forma parte de la causa de pedir en la que el actor fundamenta su petitum, constituyendo un antecedente lógico que el juez debe resolver en forma previa a efectos de pronunciarse sobre la tutela solicitada. Siguiendo este criterio:

"(...) cuestión prejudicial en un sentido lógico es, por ejemplo, la relativa a la existencia o validez de un contrato cuyo cumplimiento se pide; o cuando se reclama el pago de un alquiler y se cuestiona la existencia del arrendamiento; o cuando en una demanda de alimentos hecha valer por o contra el hijo se cuestiona el estado o status de hijo"50.

47 Sobre la materia, ver ampliamente Rivero (2016), pp. 40 y ss.

${ }^{48}$ En esta línea, Chiovenda (1936), pp. 421-427 y Chiovenda (2000), pp. 733-741. A partir de la idoneidad para constituir objeto de un proceso autónomo como requisito de la prejudicialidad, este autor realiza una revisión casuística de los casos que a su juicio constituyen supuestos de prejudicialidad. Desde esta perspectiva, a su juicio, por su propia naturaleza tendrán el carácter de prejudicial las cuestiones relativas a un estado o condición jurídica, como ocurre con el estado civil; las cuestiones relativas a la existencia de una relación jurídica compleja; la cuestión sobre la existencia de una relación jurídica con obligaciones a plazo; la cuestión que se plantea sobre la existencia de una relación jurídica condición de la principal y la cuestión relativa a la existencia de una relación jurídica incompatible con la principal, como ocurre en aquellos casos en que en una acción reivindicatoria el demandado afirma su calidad de dueño de la cosa.

49 Satta (1971), pp. 44-46. También en Satta (1958), pp. 243-246; SatTA (1947), pp. 29 y ss. y Satta (1948), pp. 64 y ss. Esta distinción es seguida en Italia principalmente por MENCHINI (1987), pp. 140 y ss. y Proto (1999), pp. 353 y ss.

${ }^{50}$ En esta línea, existen cuestiones que el juez debe "por su naturaleza o por su relación con la cuestión principal, conocer con eficacia de cosa juzgada, o que quedan precluidas del juicio como consecuencia del pronunciamiento del juez". Si bien estas cuestiones se encuentran vinculadas 
En cambio -en lo que para Satta constituye la denominada prejudicialidad técnica- la cuestión prejudicial tiene que ver:

"(...) con una relación o situación jurídica diversa e independiente del hecho constitutivo hecho valer en juicio, pero que, sin embargo, se presenta como presupuesto lógico-jurídico de aquel. En este caso, la cuestión no forma parte de la causa de pedir de la pretensión, pero tiene la aptitud de excluir la consecuencia jurídica perseguida por el actor. Tal es el caso, por ejemplo, cuando demandado un deudor por el heredero del acreedor, se cuestiona o discuta la calidad de heredero y en general, todas aquellas hipótesis en que un derecho o relación jurídica actúa como elemento o hecho constitutivo, modificativo, impeditivo o extintivo de una cuestión de la que se deriva, como efecto jurídico, un diverso derecho o relación ${ }^{\prime \prime 5}$.

Estas cuestiones pueden ser decididas tanto en el mismo proceso, discutiéndose en doctrina la eficacia de cosa juzgada de dicha decisión, o bien y desde luego, mediante una acción meramente declarativa o de certeza, a fin de que sea resuelta como objeto de un proceso autónomo con eficacia de cosa juzgada.

Fuera de lo anterior, y alejándose de la tradicional concepción imperante bajo la concepción del Estado liberal de derecho sobre la función represiva de la jurisdicción, en general y de la tutela civil, en particular, parte mayoritaria de la doctrina asigna a la tutela de mera certeza una función esencialmente preventiva, esto es, se trata de una tutela dirigida a evitar o prevenir la lesión de derechos derivada de una situación de incertidumbre jurídica, mediante la intervención temprana del juez ${ }^{52}$.

Lo anterior significa afirmar, en definitiva, que este tipo de tutela judicial civil, para poder operar, no requiere que exista una violación o lesión de

desde un punto de vista lógico a la cuestión principal, no son cuestiones prejudiciales en sentido estricto porque "están sin duda comprendidas en el objeto del juicio" (y) "atañen siempre al hecho constitutivo del derecho que se hace valer". En definitiva, estas cuestiones se deducen siempre en «relación a la determinada pretensión que se hace valer". SATTA (1971), pp. 45 y ss., y Rivero (2016), pp. 39 y ss. y pp. 219 y ss.

51 SATta (1971), p. 45 y Rivero (2016), pp. 40 y 220 y ss. Para Proto (1999), pp. 354 y 355, en estos casos el nexo de prejudicialidad-dependencia transcurre entre relaciones jurídicas diversas, donde la existencia de una depende de la existencia o inexistencia de la otra, dando siempre lugar a un fenómeno de conexión entre objetos procesales. Es en este sentido, en su opinión, que se dice que una relación jurídica es prejudicial respecto de otra y que esta última es dependiente de la primera, pudiendo hablarse de relación condicionante y relación condicionada.

52 Por todos, Bochard (2016), pp. 68 y ss.; Carnelutti (1960), pp. 177 y ss.; Rapisarda (1987), pp. 28 y ss. 
derechos, sino que basta con que exista un riesgo de lesión de los derechos o intereses legítimos de las partes derivado de la incertidumbre o falta de certeza sobre los mismos ${ }^{53}$.

La incertidumbre constituye, en consecuencia, el presupuesto clave que debe concurrir para que la acción de mera certeza cumpla con su función preventiva y es exigible en la medida que la tutela que se solicita va a resolver un asunto controvertido con eficacia de cosa juzgada, de manera tal que, tal como señala la doctrina, el simple "interés subjetivo, en sí mismo considerado y pese a existir, no es ni puede ser, en los ordenamientos jurídicos actuales presupuesto de una tutela de mera declaración, ni mucho menos motor de la misma" ${ }^{\prime 4}$.

Al efecto, y atendido que la determinación de la incertidumbre es una cuestión que deberá verificar el juez caso a caso, la doctrina menciona, al menos, tres requisitos esenciales para su valoración: (i) debe ser objetiva y actual, lo que significa en esencia que no puede recaer sobre simples hechos, debe ser real en el momento de interposición de la demanda y no referirse a un momento futuro; (ii) debe derivar de actos u omisiones imputables al demandado y (iii) debe ser una incertidumbre y amenaza de perjuicio del actor evitable solo mediante el pronunciamiento judicial de certeza ${ }^{55}$.

Para Chiovenda esta situación de incertidumbre o falta de certeza sobre los derechos o relaciones entre las partes que se pretende prevenir o evitar con la declaración de mera certeza, puede derivar de diversas situaciones ${ }^{56}$.

Así en primer lugar, puede existir una incertidumbre por insuficiencia probatoria, como ocurre en el caso que se alegue la falsedad de un documento; o por apariencia del acto jurídico, como ocurre en los casos de simulación; por negación del derecho del actor o afirmación de un derecho a cargo del

\footnotetext{
${ }^{53}$ Bajo la concepción del Estado constitucional de Derecho, con todo, y junto con cuestionar el carácter meramente represor de la jurisdicción, para la doctrina este tipo de tutela preventiva, si bien necesaria, sería insuficiente para otorgar una protección eficaz de los derechos de los ciudadanos. Por ello, a partir de un nuevo entendimiento de la tutela cautelar, ha venido reclamando la necesidad de reconocer y regular otras formas de tutela preventiva, más incisivas e idóneas que la meramente declarativa, como la denominada tutela inhibitoria, la que debiera admitirse como una forma de tutela atípica general. Sobre la materia, ver Bordalí (2001), pp. 60 y ss.

${ }^{54}$ CALDerón (2008), p. 262. Citando a Allorio, la autora toma el ejemplo de este autor cuando señala que, así, "al propietario que pretenda la declaración de certeza en juicio de su derecho, mientras no hay incertidumbre alguna que dirimir a su respecto, ni proveniente de contestación ajena ni de otra fuente, (...), se le podrá oponer la falta de interés en la tutela declarativa".

55 Sobre estos requisitos, ver ampliamente Calderón (2008), pp. 252 y ss. y Díez-Picazo (1998), pp. 357 y ss.

${ }^{56}$ Chiovenda (2016), pp. 10, 11, 34-36.
} 
actor; falta de certeza de la persona titular del derecho o falta de certeza de una cláusula contractual o disposición testamentaria. Asimismo, y como se ha visto previamente, una función esencial que cumple la tutela meramente declarativa es la de poner fin a la inseguridad o falta de certeza prejudicial de un derecho, relación o situación jurídica prejudicial a la que se discute como objeto principal del pleito ${ }^{57}$.

Como se ha visto, la jurisprudencia en Chile ha hecho eco de este requisito o presupuesto al sostener que:

"El actor que pide una sentencia de declaración quiere solamente saber si su derecho existe, o quiere excluir toda duda sobre la existencia del derecho ajeno; pide al proceso la certidumbre jurídica y no otra cosa (...). Esta producción de la certidumbre jurídica como fin en sí misma es, por una parte, la función más autónoma del proceso, porque procura un bien que no puede conseguirse de otra manera y es realmente la función más elevada del proceso civil" ${ }^{28}$.

Con todo, y como tempranamente lo ha venido estableciendo la justicia en Estados Unidos a propósito de los declaratory judgments, este carácter preventivo de la tutela de mera certeza no quiere decir que la jurisdicción tiene o puede tener una función de advisory opinion ${ }^{59}$, es decir, de mero consejo u opinión sobre la aplicación de la ley respecto de hechos no controvertidos y sin fuerza vinculante para el futuro, ni menos:

"(...) la de decidir un "moot case", o sea, dar un simple dictamen acerca de una controversia ficticia, simulada, hipotética, abstracta, académica o muerta" ${ }^{60}$.

Por el contrario, la doctrina es categórica en afirmar que la jurisdicción no tiene una función meramente retórica o académica ni consultiva, sino que está para resolver conflictos de relevancia jurídica de manera tal que la tutela de mera certeza exige, al igual que en la tutela constitutiva y de condena, la existencia de una controversia o discusión actual sobre la existencia

\footnotetext{
57 Chiovenda (2016), pp. 34-36.

58 Sentencia Corte de Apelaciones de Santiago, (sin $N^{\circ}$ de rol), de 30 de diciembre de 1983, confirmada, con modificaciones, por Sentencia Corte Suprema ( $\sin \mathrm{N}^{\circ}$ de rol), de 13 de noviembre 1985.

59 Chiovenda (2016), pp. 14 y ss.; Goldschmidt (2016), pp. 280 y ss. y Borchard (2016), pp. 68 y 69.

60 Goldschmidt (2016), p. 280.
} 
o inexistencia del derecho o relación jurídica y que justifica que ésta sea declarada con eficacia de cosa juzgada ${ }^{61}$.

Con base en lo anterior, un sector de la doctrina ha llegado incluso a cuestionar la función preventiva que se atribuye a la tutela de mera certeza entendiendo que la incertidumbre no es presupuesto ni requisito de este tipo de acción por cuanto el término "duda conduce a consulta, no siendo la jurisdicción de índole consultiva". A diferencia de los asuntos no contenciosos o meramente consultivos:

"(...) en la pretensión meramente declarativa sí existe caso, el cual no radica en la incertidumbre ni en una consulta, sino en la necesidad de la declaración que tiende a brindar seguridad jurídica, pues será mediante este mero acertamento que se obtiene el beneficio de fijeza componiendo un litigio determinado. Y esa fijeza es lo buscado, no el prevenir"62.

En definitiva, y aun cuando se predique o niegue respecto de la acción declarativa una función preventiva, lo relevante es que la tutela de mera certeza no constituye ni puede ser concebida como una función meramente consultiva o no contenciosa de los tribunales de justicia, la que por lo demás, como es sabido, requiere de habilitación legal expresa ${ }^{63}$, de manera tal que es necesario excluir de este tipo de tutela todas aquellas peticiones o demandas que "no impliquen ejercicio de potestad jurisdiccional"64.

Por ello, es imprescindible que el sujeto que solicita la tutela acredite la existencia de una controversia, duda o incertidumbre actual que produce o puede producir una lesión a un derecho o interés legítimo de que es titular y que solo es reparable con la intervención y declaración del juez.

En esta línea, para Romero, como requisito esencial de la acción de mera certeza, lo importante en este caso es que ésta no puede recaer sobre "situaciones hipotéticas o futuras, sino sobre una controversia actual" siendo necesario

\footnotetext{
${ }^{61}$ Para ChIOvenda (2016), p. 34, "las sentencias declarativas no pueden, además, confundirse con simples resoluciones académicas o con simples dictámenes (...). Las sentencias declarativas tienen un alto valor práctico, porque vinculan a las partes con efecto de cosa juzgada; su valor es igual al de las sentencias de condena, salvo que la parte que obtiene la sentencia, no tiene necesidad de otra defensa que aquella que nace de la simple declaración del derecho".

62 González (2007), pp. 205 y 206.

${ }^{63}$ Tal es el caso en Chile, del Tribunal de Defensa de la Libre Competencia, el que detenta una potestad consultiva contemplada en el art. 18 D.L. № 211 (D.F.L. № 5, 2015, Ministerio de Economía). Sobre la materia, ver Fuenzalida y ValderRAma (2004), pp. 181-198.

${ }^{64}$ Calderón (2008), p. 327.
} 
además, como se verá en el apartado siguiente, que exista un interés jurídico que justifique la tutela lo que:

"(...) descarta que se promuevan consultas puramente doctrinales o académicas, ya que la jurisdicción solo actúa para la resolución de controversias jurídicas intersubjetivas" ${ }^{\prime \prime}$.

\subsection{Tercer requisito: existencia de un interés jurídico que justifique la necesidad de la tutela solicitada. El riesgo de perjuicio}

Un tercer presupuesto de la acción de mera certeza, y a juicio de la doctrina el más importante, pero a la vez difícil de determinar ${ }^{66}$, es la existencia de un interés jurídico legítimo "que justifique la necesidad de conceder este tipo de protección" ${ }^{67}$, interés que "está integrado por los hechos que generan una inseguridad-incertidumbre-jurídica perjudicial al titular del derecho" ${ }^{\prime \prime 6}$.

En términos generales, como señala la doctrina, los ordenamientos europeos exigen el interés como presupuesto de admisibilidad de la acción y sentencia de mera declaración existiendo en todos aquellos casos en que: "(...) el actor se encuentra en un estado de incertidumbre o inseguridad perjudicial a su situación jurídica y ese estado puede ser removido por la mera declaración del tribunal. No es necesario que el derecho cuya declaración se solicita haya sido violado; basta que el demandado lo discuta, desacate o se jacte de tener un derecho cuya no existencia deba declararse", debiendo rechazarse la acción cuando "el actor se encuentra colocado en la situación de poder intentar la correspondiente acción de condena o constitutiva"69.

En la misma línea, para Chiovenda este interés concurre cuando la declaración solicitada se presenta como necesaria o indispensable para asegurar la condición jurídica del actor frente al demandando y consiste, en esencia:

\footnotetext{
${ }^{65}$ Romero (2007), pp. 34-36.

${ }^{66}$ Chiovenda (2016), pp. 7 y 35. Por ello, tal como advierte este autor, aquí entra en juego la necesaria "prudencia que debe tener el magistrado en la valoración de esta necesidad, caso por caso, para evitar eventuales abusos, como pueden ser los juicios colusivos o ficticios, las acciones inconsideradas o vejatorias".

67 Romero (2007), p. 36.

${ }^{68}$ Ortells (2015), p. 181.

${ }^{69}$ RosenberG (2016), pp. 52 y 53.
} 
"(...) en una situación de hecho tal que el actor, sin la declaración judicial de certeza sufriría un daño, de modo que la declaración judicial se presenta como el medio necesario para evitar este daño"70.

En definitiva, se ha entendido que la tutela jurisdiccional de mera declaración no existe ni es procedente si no se prueba o acredita la verdadera necesidad de una declaración inmediata de certeza del derecho, relación o situación jurídica que se discute, que evite un riesgo de perjuicio futuro, interés que no puede confundirse, con todo, con la legitimación ni la titularidad del derecho sustancial ${ }^{71}$.

Dicho interés deberá ser alegado y probado por quien solicita la tutela y debe ser actual y de carácter jurídico "no meramente moral, o científico o de amistad" y consiste principalmente "en la negación que otro haga del derecho del actor, o viceversa en la afirmación de un derecho a cargo del actor ${ }^{\prime \prime 2}$.

En esta línea, y en conexión con el requisito de existencia de una incertidumbre, se entiende que no existe interés legítimo en accionar cuando los hechos que integran o generan la incertidumbre jurídica no producen beneficio o perjuicio al actor, o bien, aunque existente, el perjuicio no puede ser reparado a través de la eficacia de cosa juzgada de la sentencia declarativa ${ }^{73}$.

Como se ha visto precedentemente, la jurisprudencia chilena ha recogido y resuelto la procedencia de este requisito especialmente a propósito del conocimiento de acciones de mera certeza deducidas entre entes públicos o por particulares en contra de la administración del Estado, por ejemplo, en materia tributaria, admitiendo la acción de mera declaración cuando existe duda acerca del derecho aplicable a un determinado organismo o situación, o bien sobre la interpretación de una determinada norma jurídica y la intención del legislador para su establecimiento ${ }^{74}$.

\footnotetext{
${ }^{70}$ Chiovenda (2016), p. 35. En esta línea, señala este autor que, en derecho alemán, el interés jurídico que justifica la petición de tutela consiste "en un estado real de falta de certeza o de inseguridad tal que amenace la condición jurídica del actor y que justifique la necesidad de una inmediata aclaración aun solo para obtener de ella una norma para su futura conducta, como en el caso de negación de su derecho o de jactancia de derecho por parte de otro, o en el caso de que exista peligro de prescripción".

71 Calderón (2008), pp. 229 y ss.

72 Calderón (2008), p. 10.

73 Calderón (2008), pp. 296 y 297.

74 Así, frente a la una demanda de certeza deducida por un particular frente a la duda sobre la validez del pago realizado de un tributo, la Corte ha sostenido que "(...) al existir una verdadera contienda entre las partes en cuanto a la interpretación y alcance de una norma legal de carácter tributario, resulta plenamente válida la intervención del tribunal a fin de dar certeza y seguridad en esta relación jurídica y justamente para terminar con esa incertidumbre, el juez es Ilamado a resol-
} 
Siguiendo lo anterior, para la doctrina, la existencia y prueba de este interés resulta imprescindible particularmente cuando la tutela de mera certeza se plantea de forma autónoma, como una acción independiente en la medida que la concurrencia de este interés es precisamente lo que permite excluir la indebida utilización de la tutela judicial con fines meramente consultivos o académicos, debiendo probarse la existencia de una necesidad verdadera y actual de tutela sólo realizable mediante la declaración de mera certeza ${ }^{75}$.

Por el contrario, no sería necesario probar la existencia de este interés legítimo en aquellos casos de prejudicialidad o falta de certeza prejudicial del derecho antes vistos, es decir, cuando en el contexto de una acción de condena o constitutiva, las partes controvierten algún derecho o relación jurídica que constituye el presupuesto de la tutela solicitada o bien de cuya existencia o inexistencia depende el otorgamiento o denegación de la tutela requerida. Como ocurre, por ejemplo, cuando en el contexto de una acción reivindicatoria, el demandado cuestiona, vía reconvención, la titularidad del derecho de propiedad del demandante o en un juicio de filiación o alimentos se cuestiona el estatus de padre o hijo o en una acción de petición de herencia, se cuestiona la veracidad del testamento. Se trata, en definitiva, de supuestos en los que la petición declarativa se inserta dentro de una acción o tutela de condena o constitutiva ${ }^{76}$.

Ahora bien, cuando la controversia dice relación con la interpretación de cláusulas testamentarias o contractuales en que lo que se pretende es una interpretación vinculante del juez para las partes, la tutela de mera declaración se admite solo en la medida que se persiga prevenir un litigio futuro, evitando que las partes realicen o sigan realizando: "(...) actos materiales u omisiones de conformidad con la interpretación de la cláusula por ella sostenida y que surja un juicio sobre la ilegalidad del hecho realizado y sobre sus consecuencias civiles y penales", con lo cual "se tiende a prevenir una actividad ilegal resolviendo la cuestión previamente", evitando así daños, responsabilidades y gastos futuros ${ }^{77}$.

ver el conflicto". Sentencia Corte de Apelaciones de Santiago ( $\sin \mathrm{N}^{\circ}$ de rol), de 30 de diciembre de 1983, p. 124. Sobre estas acciones, ver ampliamente Sото (2017a), pp. 503-514; Sото (2017b), pp. 94-114 y ROMERo (2007), pp. 34-37.

75 Chiovenda (2016), pp. 10 y ss.

${ }^{76}$ Chiovenda (2016), pp. 10 y 11.

77 Chiovenda (2016), p. 36. 


\subsection{Cuarto requisito: Inexistencia de otras acciones adecuadas para la tutela del derecho. El carácter subsidiario de la acción de certeza}

Finalmente, y principalmente por la influencia del Derecho alemán e italiano, parte importante de la doctrina, no sin importante discrepancia de algunos autores ${ }^{78}$, sostiene el carácter restrictivo o excepcional de la tutela de mera certeza entendiendo que esta es inadmisible o improcedente cuando el demandado tiene a disposición o está en posición de ejercer otras acciones más incisivas o eficaces para la tutela de su derecho.

Se afirma así el carácter subsidiario de la acción de mera declaración fundado, esencialmente, en la economía procesal y la falta o inexistencia de interés legítimo de accionar cuando la parte puede conseguir la certeza jurídica por otra vía, especialmente en juicio de condena. Así, a juicio de Chiovenda, la economía de los procesos impide que la acción de certeza sea "admitida cuando el actor tenga a su disposición un medio de defensa más amplio, como la sentencia de condena o la sentencia constitutiva, con tal que sirva también para satisfacer el interés en la declaración de certeza"79.

En nuestro concepto, lo cierto, sin embargo, es que la tutela constitutiva, de condena y certeza tienen carácter autónomo e individualidad propia y, por tanto, una restricción a las partes para el acceso a la tutela de mera declaración en forma subsidiaria debe ser interpretada con la cautela que exige el derecho de acceso a la justicia y la tutela judicial efectiva.

Consideramos, con todo, que sí es necesario que el legislador establezca un tratamiento procesal coherente y armónico frente a la concurrencia de este tipo de acciones que evite un goteo sucesivo e ilimitado de pretensiones respecto de un mismo derecho, relación o situación jurídica, lo que normalmente ocurrirá cuando la pretensión de certeza no satisfaga completamente la necesidad de tutela del derecho, siendo necesario iniciar posteriormente un proceso condenatorio.

Ello por cuanto, tal como señala la doctrina, uno de los principales problemas que conlleva aceptar la procedencia paralela o sucesiva de pretensiones de mera certeza con acciones de condena o constitutivas es que ello importa obligar al sujeto pasivo a verse "involucrado dos o más veces en un proceso por el mismo asunto litigioso". A lo anterior, se agrega la dificultad adicional de no poder alegar la litispendencia como anticipación de la eficacia negativa

${ }^{78}$ Calderón (2008), pp. 336 y ss.

${ }^{79}$ Chiovenda (2016), p. 33. 
o excluyente de la cosa juzgada al no darse las identidades necesarias para ello, atendido a que el petitum en una y otra pretensión es diferente ${ }^{80}$.

Fuera de lo anterior, a nuestro juicio y tal como se señala a propósito del ordenamiento alemán, más que ser entendida como una restricción general de acceso a la tutela de certeza, esta limitación debe ser mirada desde la perspectiva del interés del actor en la solicitud de tutela el cual, en definitiva, desaparece y debe retroceder cuando existen otros medios o acciones "más especializadas o avanzadas con las que resulte viable examinar la demanda de manera concluyente o aclarar en su integridad la relación litigiosa entre las partes" ${ }^{\prime \prime 1}$.

En definitiva, y tal como ocurre en los sistemas del common law, en nuestra opinión y cumpliéndose los requisitos antes examinados, la pretensión meramente declarativa constituye la tutela base de nuestro sistema procesal a la cual siempre pueden recurrir los justiciables con carácter principal, y no meramente subsidiario, para solicitar, como objeto autónomo de un proceso, la certeza prejudicial de sus derechos e intereses legítimos y/o poner fin, preventivamente, a un estado de incertidumbre jurídica.

\section{Efectos y cumplimiento de la sentencia meramente declarativa}

Nos referiremos, por último, a un par de cuestiones procesales interesantes a que dar lugar la acción de mera certeza y que dicen relación, esencialmente, con los efectos y cumplimiento de la sentencia de mera declaración y la forma de oponerse a dicho cumplimiento.

Constituyendo una pretensión innominada de carácter principal y autónomo, por aplicación del art. $3^{\circ}$ del Código de Procedimiento Civil, la acción meramente declarativa debe ser deducida ante el tribunal competente ratione materiae a través de un juicio ordinario de lato conocimiento y será resuelta mediante sentencia definitiva con eficacia de cosa juzgada material (arts. 175 y 177 del mismo Código).

Característica principal de la sentencia meramente declarativa que se dicte en el proceso es su eficacia retroactiva $(e x t u n c)^{82}$, y que no requiere de ejecución o cumplimiento forzado, en tanto la tutela se satisface con su mero pronunciamiento, proyectándose la eficacia de la cosa juzgada material y los efectos vinculantes o prejudiciales de la sentencia respecto de cualquier

80 Calderón (2008), pp. 347 y ss.

81 Calderón (2008), p. 336.

82 Para la doctrina, lo cierto, sin embargo, es que la sentencia declarativa "no crea derechos retroactivamente, sino que simplemente reconoce derechos preexistentes". CALDERón (2008), p. 198. 
proceso seguido entre las mismas partes ${ }^{83}$, eficacia que, en el ámbito del Derecho Administrativo, para parte de la doctrina tendría incluso carácter erga omnes, vinculando a la administración en todos aquellos casos futuros en que la situación sea idéntica ${ }^{84}$.

Siguiendo lo anterior, y cumpliéndose los requisitos, la sentencia meramente declarativa produce eficacia de cosa juzgada material, tanto de naturaleza negativa o excluyente como positiva o prejudicial, $y$, al igual que las sentencias constitutivas, no es susceptible de ejecución pues se bastan y cumplen por sí mismas con su solo pronunciamiento.

Esta es la razón, como se ha visto, por la cual el Proyecto de Nuevo Código Procesal Civil (arts. 234 y ss.) excluye esta categoría de sentencias de la posibilidad de ejecución provisional, la que es aplicable solo respecto de sentencias condenatorias.

Con todo, la eficacia y efectividad práctica de la sentencia de mera declaración requiere, y hace muchas veces necesaria, la orden y realización de actos de cumplimiento (no de ejecución) complementarios o accesorios no ejecutivos, que hagan viable y materialmente posible la tutela concedida y sin los cuales, se transformaría en una tutela de papel.

Se trata de actos consecuenciales o complementarios no ejecutivos que permiten, en definitiva, reforzar la efectividad de la sentencia sea por vía de publicidad, como ocurre en general con las inscripciones registrales -como la que exige nuestro art. 2513 CC para la sentencia que declara la prescripción adquisitiva-, como también mediante la realización de otros actos de

83 Ortells (2016), p. 57; Romero (2007), p. 37.

${ }^{84}$ A juicio del Prof. Sото (2017a), pp. 511 y 512, "Si la pretensión es acogida por el tribunal y la sentencia definitiva queda ejecutoriada, ella produce cosa juzgada material, lo que significa que es no sólo irrecurrible sino, además, inamovible. (...) esa sentencia se le impone a la Administración no sólo respecto del acto referido sino también en todos los casos en que la situación sea idéntica, pues ha sido declarado el Derecho erga omnes en tal caso, sea en cuanto qué Derecho es aplicable, en cuanto a cómo debe interpretarse determinados preceptos legales, sea en cuanto a establecer cuál ha sido la voluntad del legislador". A nuestro juicio, con todo, esto no es un problema de eficacia erga omnes de la sentencia declarativa ni menos aún de extensión ultra partes de la eficacia positiva o prejudicial, que podría ser cuestionable desde el punto de vista constitucional en virtud del derecho de defensa de los terceros que no han intervenido en el juicio y del principio de la res iudicata inter partes, sino de sujeción al mandato o precedente sentado por la justicia en un caso concreto, el cual, a nuestro juicio y para otros casos similares, pero con diversas partes intervinientes, no resulta vinculante. Por esta misma razón, el propio Tribunal Constitucional, fallando la contienda de competencia, ha señalado que mediante una acción de mera certeza los tribunales no pueden entrar a interpretar de forma abstracta, genérica y retroactiva los textos constitucionales y legales que gobiernan la materia, ni se puede pretender que dicha interpretación es aplicable de forma genérica a todos los funcionarios de una repartición, debiendo resolverse caso a caso. Sentencia Tribunal Constitucional, rol №3283-16 CCO, de 18 de enero de 2017. 
cumplimiento que son aceptados en algunos ordenamientos comparados, como la cancelación y rectificación de inscripciones; la orden de dividir la cosa común; extinción y constitución de tutelas y curatelas; liquidación de bienes o sociedades e incluso la reintegración y devolución de dinero y cosas derivadas de una declaración de nulidad e incluso la propia demolición de una construcción, como ocurre en España ${ }^{85}$.

Es lo que la doctrina denomina como ejecución impropia, en la cual lo relevante es que se ordene la realización de actos complementarios que permitan reforzar la efectividad práctica de la resolución dictada, pero que no signifiquen el uso del poder coercitivo del tribunal ${ }^{86}$.

Ahora bien, la orden y realización de este tipo de actos puede generar no pocos problemas con relación al principio de congruencia, atendido que se tratará, normalmente, de la realización de actuaciones que no han sido parte del objeto del proceso declarativo ni han sido solicitadas expresamente por las partes.

Sobre la materia, a efectos del deber de congruencia y la existencia de ultra petita, la jurisprudencia y doctrina españolas han entendido que dicha infracción no se produce en la medida que la petición haya sido acogida (i) sin variación de la acción principal ejercitada, (ii) sin indefensión flagrante de la contraparte, (iii) el ajuste del fallo sea en línea de necesaria racionalidad, flexible y de posible cumplimiento del fallo, (iv) que las cuestiones acogidas sean accesorias o complementarias, ( $v$ ) que sean propias y necesarias, y (vi) que hayan estado comprendidas en el objeto del debate e implícitamente en las solicitudes de las partes ${ }^{87}$.

85 Cово (1995), pp. 102 y ss.

86 Sobre la materia en derecho español, ver ampliamente CALDERÓn (2008), pp. 576 y ss.

$87 \mathrm{Al}$ efecto, se ha entendido que no incurre en ultra petita la sentencia que acoge aspectos complementarios o accesorios que están sustancialmente comprendidos en el objeto del debate e implícitamente en las pretensiones deducidas en la demanda, señalando que "es reiterada la doctrina de esta Sala la de que la armonía o concordancia entre los pedimentos de las partes y la sentencia, en que consiste la congruencia, no implica necesariamente un ajuste literal a lo suplicado, sino una racional adecuación del fallo a las peticiones de los litigantes y al supuesto fáctico ("causa petendi") en que se basan, lo que permite hacer extensivo el fallo a las consecuencias lógicas y naturales derivadas del tema debatido (...) en cuanto aparezca probado que ello es necesario para el logro de dicha reparación". En la misma línea, se ha sostenido que "no se produce incongruencia por exceso cuando la resolución judicial otorga, además de lo expresamente pedido, todo aquello que sea antecedente o consecuencia necesaria del pedimento".

Siguiendo este criterio, se ha considerado, por ejemplo, que la demolición de lo edificado no quebranta lo pedido en el suplico sino que se atiene a él por ser una consecuencia lógica y jurídica de la acción reivindicatoria acogida, Ilevando consigo también la cancelación de las inscripciones registrales contradictorias. A juicio de la Corte, de no pronunciarse el fallo sobre estas cuestiones "quedaría sin efecto el derecho de disposición sobre la cosa que la ley atribuye al propietario (...) 
En definitiva, junto al carácter complementario o accesorio, la cuestión otorgada debe ser necesaria y propia para el cumplimiento de la sentencia; no importar un cambio del objeto del proceso, del objeto pedido ni la causa de pedir y debe haber estado comprendida en el objeto del debate e implícitamente en las solicitudes de las partes, sin causar indefensión de la contraparte ${ }^{88}$.

Siguiendo lo anterior, y atendido que las sentencias meramente declarativas se bastan a sí mismas y por tanto, como se ha dicho, no se ejecutan sino que se cumplen, la denominada ejecución impropia cobra especial relevancia respecto de este tipo de tutela a fin de evitar que la sentencia meramente declarativa sea un mandato vacío e inútil.

En esta línea, consideramos que los tribunales no solo pueden sino que tienen la obligación de ordenar las consecuencias y la realización de los actos necesarios de cumplimiento que aseguren la eficacia de la sentencia, aun cuando dichos actos -y siempre que se cumplan los requisitos antes señalados- no hayan sido expresamente solicitados por las partes.

Finalmente, una cuestión procesal adicional, que plantea la tutela de mera declaración, dice relación con los instrumentos o vías procesales que tendrían los terceros interesados o indiferentes para oponerse a dicha sentencia y enervar sus efectos cuando se pretende hacerla valer en su contra, sin haber tenido ocasión de litigar ni defenderse en el juicio entre partes.

Al respecto, cabe relevar la importancia y atención que otros sistemas comparados, como el italiano y francés, asignan con esta finalidad a la inoponibilidad y en especial al mecanismo de oposición de tercero a la cosa juzgada en virtud del cual se puede llegar a obtener incluso, la nulidad de la sentencia inter alios que se pretende hacer valer contra el tercero con infracción de su derecho de defensa ${ }^{89}$.

Sobre la materia, el ordenamiento chileno sólo contempla parcialmente instrumentos para hacer valer la inoponibilidad estableciendo, en el art. 234,

con lo que resultaría ficticia la estimación de la acción reivindicatoria objeto de la Litis". Con la jurisprudencia citada, Сово (1995), pp. 102-108.

${ }^{88}$ En esta línea, para SERRA (1969), p. 409, especialmente cuando se trata de pretensiones múltiples deducidas en carácter principal, "no se incurre en incongruencia por exceso cuando se falla sobre pretensiones o cuestiones no formuladas expresamente por las partes, pero cuya resolución es previa o consecuencia de las propuestas por las partes: tales como las cuestiones que tienen carácter accesorio y son precisas para hacer viable la ejecución, o las que resuelven cuestiones prejudiciales a las propuestas, o inherentes a ellas o consecuencia obligada de las primitivas pretensiones".

89 Sobre la oposición de terceros a la cosa juzgada y en general sobre la eficacia de la sentencia respecto de terceros ver AlLorio (2014), pp. 283 y ss.; Font (1980), pp. 117-137 y Grande (2008), pp. 465 y ss. 
incisos $2^{\circ}$ y $3^{\circ}$ del Código de Procedimiento Civil (CPC), una excepción para aquellos eventos en que se pretenda ejecutar una sentencia de condena en contra de un tercero que no participó en dicho juicio, institución conocida como oposición de tercero a la cosa juzgada, y a la cual se le da una tramitación incidental ${ }^{90}$.

De este modo, si lo que se pretende es hacer valer o ejecutar una sentencia de condena, los terceros se encuentran protegidos en nuestro derecho a través de la excepción de no empecerle la misma. Tratándose de sentencias declarativas, en cambio, y atendido que éstas no son susceptibles de ejecución, cabe preguntarse cuál es la vía procesal que tendría el tercero para oponerse a dicha sentencia y enervar sus efectos.

Siguiendo la tendencia doctrinaria en la materia, y a falta de otras vías procesales explícitamente reguladas, a nuestro juicio, dicho instrumento sería la acción de inoponibilidad, materia propia de una pretensión y proceso ordinario, igualmente, de naturaleza meramente declarativa cuyo objeto, tal como señala la doctrina, no es atacar la cosa juzgada, sino impedir que la eficacia y efectos de dicha sentencia dictada entre partes alcance, sea mediante actos jurídicos o materiales, a la esfera jurídica de terceros que no tuvieron ocasión de litigar ni defenderse en el juicio entre partes ${ }^{91}$.

Desde el punto de vista del Derecho Procesal y de forma similar a lo que ocurre con los actos jurídicos civiles y el principio del efecto relativo de los contratos, la inoponibilidad de los actos jurídicos procesales y en particular de las sentencias, tiene su base en el efecto relativo de las mismas reconocido en el art $3^{\circ}$ del Código Civil, cuyo fundamento constitucional se encuentra en el principio de bilateralidad de la audiencia y de contradicción y el derecho de defensa de las partes como garantía del debido proceso y del derecho a una tutela judicial efectiva reconocidos por nuestra Constitución en el artículo $19, \mathrm{~N}^{\circ} 3^{92}$.

Se trata, en definitiva, de un mecanismo de protección de los terceros indiferentes o que han sido preteridos en un proceso en el cual tienen un interés directo o conexo cuando se pretende hacer valer en su contra una sentencia

\footnotetext{
90 Establece dicha norma que "El tercero en contra de quien se pida el cumplimiento del fallo podrá deducir, además, la excepción de no empecerle la sentencia y deberá formular su oposición dentro del plazo de diez días. La oposición se tramitará en forma incidental, pero si las excepciones no reúnen los requisitos exigidos por el inciso $1^{\circ}$ se rechazará de plano".

91 En Chile, tratan sobre este tema Colombo (1997), pp. 522 y ss.; Maturana (2015), pp. 105-107 y Romero (2011), pp. 251-264; Romero (2002), pp. 116 y 117 y Romero (2007), pp. 122 y ss.

92 Para Colombo (1997), pp. 522 y ss., "La inoponibilidad da eficacia al debido proceso al permitir a los terceros defenderse respecto de la eficacia de actos de un proceso o de una sentencia del cual no han sido partes".
} 
-en este caso meramente declarativa- que les perjudica, entendiéndose que el interés que legitima al tercero para accionar de inoponibilidad no es tanto el riesgo de ejecución, como el "estado de duda en que es puesto su derecho como consecuencia de una sentencia ajena" ${ }^{\prime 93}$, operando, en general, en todos aquellos casos de indebida o falta de configuración de un litisconsorcio necesario ${ }^{94}$.

\section{Conclusiones}

5.1. La tutela meramente declarativa es una función inherente y esencial de la potestad jurisdiccional para la protección de los derechos e intereses legítimos de los justiciables y constituye -junto con la tutela constitutiva y de condena- la tipología básica de pretensiones que es posible solicitar ante los tribunales para la declaración de existencia o inexistencia de derechos, relaciones o situaciones jurídicas o bien la determinación de la aplicación y/o interpretación de una norma jurídica a un caso concreto, poniendo fin a un estado de incertidumbre.

5.2. Es una tutela autónoma y con individualidad propia que se caracteriza por la eficacia retroactiva y de cosa juzgada material de la sentencia que la declara, la que no es susceptible de ejecución sino solo de cumplimiento. En esta línea, adquieren un rol relevante la denominada ejecución impropia y la acción de inoponibilidad como medios para proteger a terceros que no han intervenido en el proceso.

5.3. Salvo el caso excepcional de la declaración de falsedad o falta de autenticidad de un documento, la tutela meramente declarativa al igual que la constitutiva y la de condena no tiene ni puede tener por objeto la mera declaración de existencia o inexistencia de hechos, aunque tengan relevancia jurídica, sino la certeza de derechos o relaciones jurídicas entre las partes respecto de las cuales exista controversia actual o futura.

Aceptar lo contrario importa desvirtuar la función jurisdiccional, la que está concebida para la certeza y protección de los derechos, relaciones o situaciones jurídicas reconocidos y tutelados por el ordenamiento sustantivo mediante la resolución -en este caso preventiva o prejudicial- de conflictos de relevancia jurídica, y no para la determinación y prueba de simples hechos desvinculados de toda consecuencia jurídica, y respecto de los cuales, por sí mismos considerados, no es posible que se forme cosa juzgada alguna.

93 AlLorio (2014), pp. 290 y 291.

94 Romero (2002), pp. 116 y 117 y Romero (2007), pp. 121 y ss. 
5.4. La acción de certeza tiene una finalidad preventiva o prejudicial y no meramente probatoria y/o consultiva.

A través de esta acción se busca, preventiva o prejudicialmente, la tutela de un derecho o interés legítimo a través de la declaración previa de existencia o inexistencia del derecho o situación jurídica o bien poniendo fin a un estado de incertidumbre jurídica, pero no puede ser utilizada para obtener una sentencia con finalidad meramente probatoria de hechos jurídicos $y / 0$ de opinión o para poder dar por probado el supuesto de hecho de una norma jurídica. En definitiva, no es una tutela concebida para la prueba y establecimiento de hechos jurídicamente relevantes, sino solo en la medida que ello sea necesario para la debida protección de los derechos e intereses legítimos de las personas en el contexto de una controversia actual y concreta entre partes, ni tampoco está establecida para recabar una mera consulta u opinión de un juez.

5.5. La acción de certeza exige como requisito la existencia de incertidumbre jurídica o falta de certeza prejudicial sobre derechos o relaciones jurídicas y un interés actual y legítimo que justifique la necesidad inmediata de la tutela declarativa solicitada a fin de evitar un riesgo de perjuicio solo evitable con la declaración del juez. De esta forma, la tutela jurisdiccional de mera declaración no existe ni es procedente si no se prueba o acredita la verdadera necesidad de una declaración inmediata de certeza del derecho, relación o situación jurídica que se discute, que evite un riesgo de perjuicio futuro sólo evitable mediante la declaración del juez.

5.6. La necesidad de una declaración de certeza prejudicial se presenta cuando existe incertidumbre o controversia acerca de los derechos o relaciones jurídicas en que se funda la pretensión deducida-como ocurre, por ejemplo, cuando se cuestiona la existencia o la validez del contrato cuyo cumplimiento se solicita o el estado civil o parentesco en que se funda una petición de herencia o se cuestione reconvencionalmente la calidad de dueño del bien cuya restitución de solicita- lo que hace necesario una declaración previa o prejudicial de los mismos a través de una acción meramente declarativa.

Cuando la controversia dice relación con la existencia de incertidumbre acerca de existencia o inexistencia de derechos o situaciones jurídicas, o la interpretación de cláusulas contractuales en que lo que se pretende es una interpretación vinculante del juez para las partes, la tutela de mera declaración se admite solo en la medida que se persiga prevenir un litigio futuro, evitando que las partes realicen o sigan realizando actuaciones que posteriormente puedan dar lugar a un litigio o responsabilidades y gastos futuros.

En este caso, la mera certeza se pide de forma preventiva a fin de evitar problemas o litigios futuros, pero no cuando estos se hayan ya suscitado, pues 
entonces lo que procede es la tutela de condena o constitutiva, pues los actos materiales ya se han concretado. Existiendo un proceso constitutivo-condenatorio pendiente o en curso, la incertidumbre y el interés en una declaración de certeza inmediata desaparece pues los derechos de las partes ya son objeto de tutela en otro procedimiento más incisivo y eficaz, y que constituye la vía procesal idónea y más adecuada para la tutela de los derechos e intereses que las partes estiman conculcados.

5.7. Atribuir naturaleza o carácter subsidiario a la acción de mera certeza resulta complejo desde la perspectiva del derecho de acceso a la justicia y la tutela judicial efectiva. Al mismo tiempo, sin embargo, es necesario que exista una coordinación en el ejercicio conjunto, paralelo o sucesivo de este tipo de pretensiones que impida que el sujeto pasivo se vea obligado a litigar y defenderse dos o más veces por un mismo asunto litigioso que ya es objeto de debate y tutela en un proceso constitutivo-condenatorio previo entre las mismas partes, y cuyo objeto procesal se pretende fragmentar mediante la presentación sucesiva de acciones de mera certeza. A ello, se agrega la dificultad adicional de no poder alegar la litispendencia como anticipación de la eficacia negativa de la cosa juzgada al no presentarse las identidades necesarias para ello.

5.8. En razón de lo anterior, cualquier limitación a la procedencia de la tutela de mera declaración solo puede ser mirada desde la perspectiva del interés actual del actor en la solicitud, el cual, en definitiva, desaparece y debe retroceder cuando existen otros medios o acciones más adecuados para una revisión de la relación litigiosa en su integridad y que engloban el contenido de la pretensión de certeza solicitada.

Así, la tutela de certeza debe ceder frente a la constitutiva o de condena por falta de interés cuando existen otros medios que permitan una protección más eficaz e integral del derecho o relación que se estima afectado, los que debieran ser planteados con primacía o bien de forma acumulada a la demanda de certeza. Asimismo, y con mayor razón, la tutela de mera certeza debe ceder cuando el asunto planteado como objeto del proceso de mera declaración ya forma parte del objeto de un proceso condenatorio o constitutivo previo entre las mismas partes, el que comprende y permite otorgar una tutela más integral, incisiva y efectiva a los derechos e intereses legítimos que se estiman conculcados.

En definitiva, bajo la apariencia de existencia de incertidumbre jurídica, la acción de mera certeza no puede ser utilizada para fragmentar el objeto del proceso condenatorio o constitutivo y reiterar el debate fáctico que se está produciendo en juicios pendientes entre las mismas partes, utilizando esta tutela con una finalidad meramente probatoria de hechos jurídicos y de 
opinión, lo que acerca a la labor del juez más a una función consultiva o no contenciosa que jurisdiccional.

\section{Bibliografía CitADA}

Alvear Téllez, Julio (2013): "La jurisprudencia del amparo económico. Los tres grandes déficits de la última década", en: Estudios constitucionales (Año $\left.11, N^{\circ} 1\right)$, pp. 167-220.

Allorio, Enrico (2014): La cosa juzgada frente a terceros (Traducc. M. Angélica Pulido Barreto, Madrid, Marcial Pons).

Armenta Deu, Teresa (2016): Lecciones de Derecho procesal civil, 9a edición (Madrid, Marcial Pons).

Atria Lemaitre, Fernando (2017): "El sistema de acciones reales, parte especial: acción reivindicatoria, publiciana y del art. 915)", en: lus et Praxis (Año 23, No 2), pp. 147-212.

Atria Lemaitre, Fernando (2004): "Derechos Reales", en: Revista de Derecho de la Universidad Adolfo Ibáñez ( $\left.N^{\circ} 1\right)$, pp. 21-56.

BorCHARD, Edwin (2016): "Las sentencias declarativas", en: Alsina, Hugo (director), Fundamentos del Derecho Procesal (Traducc. Martha Evelina Mercader, Argentina, Ediar), t. II, pp. 55-125.

Bordalí Salamanca, Andrés (2001): "Diversos significados de la tutela cautelar en el proceso civil", en: Revista de Derecho (Vol. XII), pp. 51-66.

Calderón, María Pía (2008): Tutela civil declarativa. De la acción a la sentencia de pura declaración (Valencia, Tirant lo Blanch).

Carneluttı, Francesco (1960): "Accertamento giudiziale preventivo", en: Rivista di Diritto Processuale (Padova, Cedam), pp. 177 y ss.

Carnelutti, Francesco (1943): "Il tema di accertamento incidentale", en: Rivista di Diritto Processuale (Vol. II), pp. 17-22.

Casarino Viterbo, Mario (2009): Manual de Derecho procesal. Derecho Procesal civil (Santiago de Chile, Ed. Jurídica), t. IV.

Chiovenda, Giuseppe (2016): "Acciones y sentencias de declaración de mera certeza", en: Alsina, Hugo (director), Fundamentos del Derecho Procesal (Traducc. Santiago Sentís Melendo, Argentina, Ediar), t. II, pp. 1-40. Este artículo corresponde a la relación general presentada por el autor al Congreso Internacional de Derecho Comparado, celebrado en La Haya, 2 al 6 de agosto de 1932, publicada en Rivista di Diritto Processuale Civile, 1933, Tomo I. 
Chiovenda, Giuseppe (2000): Principios de Derecho Procesal Civil (Traducc. J. Casaís y Santaló, Madrid, Reus), Tomo II.

Chiovenda, Giuseppe (1936): Instituciones de Derecho Procesal Civil (Traducc.

E. Gómez Orbaneja, Madrid, Ed. Revista de Derecho Privado), Vol. I.

Cobo Plana, Juan (1995): La sentencia civil (Madrid, Dykinson).

Colombo Campbell, Juan (1997): Los actos procesales (Santiago de Chile, Editorial Jurídica), t. II.

De la Oliva Santos, Andrés (2005): Objeto del proceso y cosa juzgada en el proceso civil (Navarra, Thomson-Civitas).

De Savigny, M. F. C. (1879): Sistema del Derecho Romano actual (Traducc. M. Ch, Guenoux, J. Mesía y M. Poley, Madrid, F. Góngora y Compañía, Editores), t. IV.

Díez-Picazo Giménez, Ignacio (1998): "Acciones meramente declarativas. Condena de futuro. comentario a las STS 667/1997, de 18 de julio", en: Tribunales de Justicia ( $\left.N^{\circ} 3\right)$.

Ducci Claro, Carlos (2010): Derecho Civil, Parte General (Santiago de Chile, Ed. Jurídica).

Enderle, Guillermo (1992): La pretensión Meramente Declarativa (La Plata, Ediciones Platense).

Font SerRA, Eduardo (1980): "La oposición de tercero a la cosa juzgada", en: Revista Jurídica de Cataluña (No 3), pp. 117-137.

Fuenzalida C., Pablo y Valderrama V., Mario (2004): "La potestad consultiva del Tribunal de Defensa de la Libre Competencia: ijurisdiccional o administrativa?", en: Revista de Derecho Administrativo Económico ( $\left.N^{\circ} 13\right)$, pp. 181-198.

Gimeno Sendra, Vicente (2004): Derecho Procesal Civil. I. El proceso de declaración. Parte General (Madrid, Colex).

Goldschmidt, Roberto (2016): "La sentencia declarativa", en: Alsina, Hugo (director), Fundamentos del Derecho Procesal (Argentina, Ediar), t. II, pp. 275-302.

Gómez Orbaneja, Emilio (1947): Comentarios a la Ley de Enjuiciamiento Criminal (Barcelona, Bosch), t. I.

GonzÁlez CASTRO, Manuel (2007): La acción meramente declarativa (Córdoba, Argentina, Alveroni Ediciones).

Grande Seara, Pablo (2008): La extensión subjetiva de la cosa juzgada en el proceso civil (Valencia, Tirant lo Blanch). 
Juan SÁnchez, Ricardo (2004): La responsabilidad civil en el proceso penal (Madrid, La Ley).

Larroucau Torres, Jorge (2015): "Acciones reales y estándares de prueba", en: lus et Praxis (Año 21, № 2), pp. 109-160.

LATHRop Gómez, Fabiola (2011): "Procedencia de la acción meramente declarativa del dominio en el derecho chileno", en: Ius et Praxis (Año 17, № 2), pp. 3-24

Maturana Miquel, Cristián (2015): Disposiciones comunes a todo procedimiento (separata de estudio, Facultad de Derecho, Universidad de Chile).

Maturana Miquel, Cristián (1999): Los medios de prueba (separata de estudio, Facultad de Derecho, Universidad de Chile).

Meneses PACHeCo, Claudio (2017): El documento público como medio de prueba en el proceso civil chileno (Santiago de Chile, Thomson Reuters).

MenCHINI, Sergio (1987): I limiti oggettivi del giudicato civile (Milano, Giuffrè). Murga Gener, José Luis (1983): Derecho Romano Clásico. II. El proceso (Zaragoza, Ed. Universidad de Zaragoza).

Muñoz Rojas, Tomás (1984): "Perfiles de la prejudicialidad y de otros institutos procesales afines", en: Revista Facultad de Derecho Universidad de Granada, pp. 55-66.

Ortells Ramos, Manuel (2016): Derecho Procesal Civil (Navarra, Thomson Reuters-Aranzadi).

Ortells Ramos, Manuel (2015): Derecho Procesal. Introducción (Valencia, Tirant lo Blanch).

Ortells Ramos, Manuel (2004): “Objeto, eficacia jurídica e impugnación del documento notarial", en: Revista Crítica de Derecho Inmobiliario ( $\mathrm{N}^{\circ} 684$ ), pp. 1931-1946.

Peñailillo Arévalo, Daniel (2007): Los Bienes (Santiago de Chile, Editorial Jurídica).

Proto Pisani, Andrea (1999): Lezioni di Diritto processuale civile (Napoli, Casa Editrice Dott. Eugenio Jovene).

Rapisarda, Cristina (1987): Profili della Tutela Civile Inhibitoria (Padova, Cedam).

ReCCHIONI, Stefano (1999): Pregiudizialità processuale e dipendenza sostanziale nella cognizione ordinaria (Padova, Cedam).

ReYnAl Querol, Núria (2006): La prejudicialidad en el proceso civil (Barcelona, Bosch). 
Rivero Hurtado, Renée Marlene (2016): La prejudicialidad en el proceso civil chileno. Medios procesales para la coherencia de sentencias dictadas en procesos con objetos conexos (Santiago de Chile, Thomson Reuters).

Rотн, Herbert (2013): "Comentario al artículo §256 de la ZPO", en: Stein, Friedrich y Jonas, Martin (editores), Kommentar zur Zivilprozessordnung: $Z P O, 22$. (Auflage, Band 4 §§ 253-327).

Robles Garzón, Juan Antonio (2013): Conceptos básicos de Derecho Procesal Civil (Madrid, Tecnos).

Rodríguez Papic, Ignacio (2010): Procedimiento Civil. Juicio Ordinario de Mayor Cuantía (Santiago de Chile, Editorial Jurídica).

Romero Seguel, Alejandro (2011): "La acción para la declaración de inoponibilidad de un acto o contrato", en: Zúñiga, Álex (coordinador), Estudios de Derecho privado, Homenaje Libro homenaje al jurista René Abeliuk Manasevich (Santiago de Chile, Editorial Jurídica), pp. 251-264.

Romero Seguel, Alejandro (2007): Curso de Derecho Procesal Civil. La acción y la protección de los derechos (Santiago de Chile, Editorial Jurídica), t. I.

Romero Seguel, Alejandro (2002): La cosa juzgada en el proceso civil chileno (Santiago de Chile, Editorial Jurídica).

RosemberG, Leo (2016): "Las sentencias declarativas", en: Alsina, Hugo (director), Fundamentos del Derecho Procesal (Traducc. Luis Loreto, Argentina, Ediar), t. II, pp. 303-313.

SAmper Polo, Francisco (2000): Instituciones jurídicas de Gayo: texto y traducción (Santiago de Chile, Editorial Jurídica).

Santa Cruz Serrano, Víctor (2010): "El instrumento público", en: Tavolari, Raúl (director), Doctrinas esenciales. Derecho Civil. Contratos (Santiago de Chile, Ed. Jurídica), t. I, pp. 363-395.

SATTA, Salvatore (1971): Manual de Derecho procesal civil (Traducc. Santiago Sentís Melendo y F. de la Rúa, Buenos Aires, Ediciones Jurídicas EuropaAmérica), Vol. I.

SATTA, Salvatore (1958): "Accertamento incidentale", en: Enciclopedia del Diritto (Tomo I), pp. 243-246.

SATTA, Salvatore (1948): "Nuove riflessioni in tema di accertamenti incidentali", en: Foro Italiano (Tomo I), pp. 64 y ss.

SATTA, Salvatore (1947): "Accertamenti incidentali, intervento e principi generali del diritto", en: Foro Italiano (Tomo I), pp. 29-32.

Serra Domínguez, Manuel (1969): "La incongruencia civil y penal", en: Estudios de Derecho Procesal (Ariel, Barcelona), pp. 393-432. 
Sото Kıoss, Eduardo (2017a): “La acción declarativa de mera certeza, un muy útil mecanismo procesal para hacer frente a la Administración del Estado", en: Palomo, Diego (director), Recursos Procesales. Problemas actuales (Santiago de Chile, Ediciones DER-Universidad de Talca), pp. 503-514.

Sото KLoss, Eduardo (2017b): "La acción declarativa de mera certeza frente a la administración del Estado", en: Ius Publicum ( $N^{\circ} 38$ ), pp. 94-114.

Sото KLoss, Eduardo (2012a): "La acción declarativa de mera certeza", en: Soto, Eduardo, Derecho Administrativo. Temas fundamentales, $3^{\text {a }}$ edición (Santiago, Legal Publishing-Abeledo Perrot).

Sото Kıoss, Eduardo (2012b): "Litigación judicial frente a la Administración del Estado: un recuento histórico", en: Derecho Público Iberoamericano ( $\mathrm{N}^{\mathrm{o}} 1$ ), pp. 13-23.

Sото KLoss, Eduardo (2005): "La acción declarativa de mera certeza", en: A.A. V.V., Actas XXXIV Jornadas de Derecho Público (Santiago de Chile, LexisNexis), pp. 559-566.

Ugarte Soto, Alfredo y Alonso DucCl, Julio (2011): "Las acciones declarativas o de mera certeza ante los Tribunales Tributarios y Aduaneros", en: Zúñiga, Álex (coordinador), Estudios de Derecho Privado. Libro homenaje al jurista René Abeliuk Manasevich (Santiago de Chile, Editorial Jurídica), pp. 337-350.

WACH, Adolf (1962): La pretensión de declaración (Traducc. Juan M. Sermon, Buenos Aires, Ejea).

Walker Silva, Nathalie (2015): "Sobre la posibilidad de alegar la inexistencia de un acto por vía de acción (Corte de Apelaciones de Chillán)", en: Revista de Derecho (Valdivia) (Vol. XXVIII, Nº 1), pp. 259-262.

Zuckerman, Adrian (2013): Civil Procedure Principles of Practice (Sweet \& Maxwell).

\section{NORMAS JURÍDICAS CITADAS}

Zivilprozessordnung (ZPO), art. \$256.

Ley de Enjuiciamiento Civil española de 2000.

Código de Procedimiento Civil chileno de 1903.

\section{JURISPRUDENCIA CITADA}

Otero con Falabella (1963): Juzgado Civil de Santiago $\left(4^{\circ}\right) 23$ marzo 1963 (Acción declarativa de mera certeza), en: Revista de Derecho y Jurisprudencia, Tomo 60 (1963), II, Sección Segunda, pp. 63-76. 
Businish con Cerda (1966): Corte Suprema 26 de marzo de 1966 (Acción de petición de herencia), en: Revista de Derecho y Jurisprudencia, Tomo 63 (1966), II, Sección Primera, pp. 66-88.

Cooperativa de Servicios de Agua Pichidangui Ltda. con Servicios de impuestos Internos (1985): Corte de Apelaciones de Santiago 30 de diciembre de 1983 (Acción declarativa de mera certeza), en: Revista de Derecho y Jurisprudencia, Tomo 80 (1983), II, Sección Segunda, pp. 122-126 y Corte Suprema 13 noviembre 1985, en: Revista de Derecho y Jurisprudencia, Tomo 82 (1985), II, Sección Quinta, pp. 242-245.

Ainsbury v. Millington (1987) 1 W.L.R. 379.

Televisión Nacional de Chile con Fisco (1998): Sentencia $26^{\circ}$ Juzgado Civil de Santiago 27 de julio de 1995 (Acción declarativa de mera certeza), confirmada por sentencia Corte de Apelaciones de Santiago 21 de septiembre de 1998, en: Revista de Derecho y Jurisprudencia, Tomo 95 (1998), II, Sección Quinta, pp. 252-267.

Pesquera Comercial Río Peulla S.A. con Subsecretaría de Marina (2005): Corte Suprema 26 de enero de 2005 (Acción declarativa de mera certeza), en: Cita online: CL/JUR/4860/2005, pp. 1-8.

Banco de Chile con Fisco (2009): Corte Suprema 28 de mayo de 2009 (Acción declarativa de mera certeza) en: http://vlex.com/vid/-332711318 (Id. vLex: VLEX-332711318), pp. 1-17.

Comunidad de Aguas Canal Chufquén con González (2015): Corte Suprema 16 de diciembre de 2015 (Acción declarativa de mera certeza), en: http:// vlex.com/vid/comunidad-aguas-canal-chufquen-589726542 (Id. vLex: VLEX-589726542), pp. 1-3.

Comicheo Espinosa con Sociedad Lagosmaq Limitada (2015): Corte Suprema 3 de marzo de 2015 (Despido injustificado), rol No 8318-2014, pp. 1-4.

Jaramillo Flores con Centro de Capacitación Campus Patagonia S.A. (2016): Corte Suprema 17 de noviembre de 2016 (Despido injustificado), rol No 28657-16, pp. 1-16.

Contraloría General de la República con 29Juzgado Civil de Santiago (2017): Tribunal Constitucional, 18 de enero de 2017, rol № 3283-16 CCO (Contienda de competencia). 
